\title{
Glial Cells: Role of the Immune Response in Ischemic Stroke
}

\author{
Shenbin $\mathrm{Xu}^{1 \dagger}$, Jianan $\mathrm{Lu}^{1 \dagger}$, Anwen Shao ${ }^{1 \dagger}$, John H. Zhang ${ }^{2,3,4 *}$ and Jianmin Zhang ${ }^{1,5,6 *}$ \\ ${ }^{1}$ Department of Neurosurgery, The Second Affiliated Hospital, School of Medicine, Zhejiang University, Hangzhou, China, \\ ${ }^{2}$ Department of Physiology and Pharmacology, School of Medicine, Loma Linda University, Loma Linda, CA, United States, \\ ${ }^{3}$ Department of Anesthesiology, School of Medicine, Loma Linda University, Loma Linda, CA, United States, ${ }^{4}$ Department of \\ Neurosurgery, School of Medicine, Loma Linda University, Loma Linda, CA, United States, ${ }^{5}$ Brain Research Institute, Zhejiang \\ University, Hangzhou, China, ${ }^{6}$ Collaborative Innovation Center for Brain Science, Zhejiang University, Hangzhou, China
}

Ischemic stroke, which accounts for $75-80 \%$ of all strokes, is the predominant cause of morbidity and mortality worldwide. The post-stroke immune response has recently emerged as a new breakthrough target in the treatment strategy for ischemic stroke. Glial cells, including microglia, astrocytes, and oligodendrocytes, are the primary components of the peri-infarct environment in the central nervous system (CNS) and have been implicated in post-stroke immune regulation. However, increasing evidence suggests that glial cells exert beneficial and detrimental effects during ischemic stroke. Microglia, which survey CNS homeostasis and regulate innate immune responses, are rapidly activated after ischemic stroke. Activated microglia release inflammatory cytokines that induce neuronal tissue injury. By contrast, anti-inflammatory cytokines and neurotrophic factors secreted by alternatively activated microglia are beneficial for recovery after ischemic stroke. Astrocyte activation and reactive gliosis in ischemic stroke contribute to limiting brain injury and re-establishing CNS homeostasis. However, glial scarring hinders neuronal reconnection and extension. Neuroinflammation affects the demyelination and remyelination of oligodendrocytes. Myelin-associated antigens released from oligodendrocytes activate peripheral $T$ cells, thereby resulting in the autoimmune response. Oligodendrocyte precursor cells, which can differentiate into oligodendrocytes, follow an ischemic stroke and may result in functional recovery. Herein, we discuss the mechanisms of post-stroke immune regulation mediated by glial cells and the interaction between glial cells and neurons. In addition, we describe the potential roles of various glial cells at different stages of ischemic stroke and discuss future intervention targets.

Keywords: ischemic stroke, neuroinflammation, microglia, astrocytes, oligodendrocytes

\section{INTRODUCTION}

Stroke is the primary cause of severe disability and, after coronary heart disease, the second leading cause of death worldwide $(1,2)$. Ischemic stroke constitutes the greatest proportion of strokes, and accounts for $75-80 \%$ of all strokes. Several effective treatments for ischemia, such as intravenous thrombolysis and thrombectomy, which aim to restore blood flow, have emerged in recent decades. Nevertheless, the progressive neuronal degeneration and loss of function remain difficult-to-solve issues during treatment and rehabilitation. Ischemia induces cell death and cell dysfunction 
by promoting the production of proinflammatory mediators, which induce neuroinflammation. Injured and stressed cells from the ischemic core and the peri-infarct lesion release products, such as high-mobility group box 1 (HMGB1), heat shock protein (Hsp), peroxiredoxin (PRX) family proteins, interleukin (IL-) $1 \alpha$, and IL-33, which bind to pattern recognition receptors (3). Additional intracellular signaling pathways, such as nuclear factor-kappa B (NF- $\mathrm{B})$, are activated, which leads to astrocyte and microglial activation and infiltration of peripheral leukocytes (4). Neuroinflammation may reduce tissue damage by scavenging dead cells and debris; however, excessive inflammation would be detrimental because of neurotoxin production and cerebral edema (5).

Glial cells are critical components of the central nervous system (CNS) (6). Astrocytes account for 19-40\% of glial cells, whereas microglia constitute $10 \%$, oligodendrocytes constitute $45-75 \%$ of all glial cells, and the remaining cells are NG2 cells (7). Glial cells provide structural and nutritional support and are involved in the development of the CNS under normal physiological conditions. They are also critical in neuropathogenesis and in pathological conditions, as they participate in innate and adaptive immune responses. Studies have shown that glial cells regulate neuroinflammation after stroke (8-10). These cells can detect and integrate signals of neuronal damage, release cytokines, attract immune cells to the site of stroke, and interact with and affect the condition of other immune cells.

After the onset of stroke, neurons, and glial cells at the injury site immediately activate astrocytes by releasing products like damage-associated molecular pattern molecules (DAMPs). The reactive astrocytes secrete proinflammatory cytokines, chemokines, and matrix metalloproteinases like MMP-9, which subsequently disrupt the blood-brain barrier (BBB) and recruit leukocytes from the peripheral blood (10). This contributes to secondary brain tissue damage. However, astrocytes also secrete neurotrophic factors to protect the injured site (10).

As residential immune cells, microglia respond to ischemia rapidly. Activated microglia have an essential role in regulating neuroinflammation by secreting various chemokines (5). Polarization of microglia has been extensively studied in the recent years. Microglia can express proinflammatory and antiinflammatory phenotypes during ischemic stroke. They also participate in regulating the function and status of neurons, astrocytes, and oligodendrocytes.

To date, no effective treatment has been established that targets the immune response after ischemic stroke. In this review, we analyzed the relationship between glial cells

\footnotetext{
Abbreviations: $\mathrm{BBB}$, blood-brain barrier; $\mathrm{Clq}$, complement component subunit 1q; CNS, central nervous system; DAMP, damage-associated molecular pattern; HMGB1, high-mobility group box 1 ; IFN $\gamma$, interferon- $\gamma$; IL- $1 \alpha$, interleukin 1 alpha; iNOS, inducible nitric oxide synthase; MAPK, mitogenactivated protein kinase; MCAO, middle cerebral artery occlusion; MMP, matrix metallopeptidase; PPAR, peroxisome proliferator activated receptor; Prx, extracellular peroxiredoxin; ROS, reactive oxygen species; TGF, transforming growth factor; TIM, T-cell immunoglobulin and mucin domain protein; TLR, tolllike receptor; TNF, tumor necrosis factor; TREM2, triggering receptor expressed on myeloid cells 2; VEGF, vascular endothelial growth factors.
}

and neuroinflammation, elucidated their various functions at different stages of neuroinflammation, and discussed the potential treatment targets for ischemic stroke.

\section{MICROGLIA}

More than 100 years ago, in 1913, Santiago Ramón y Cajal described microglia as the "third element" of the CNS (11). In 1918, Pío Del Río-Hortega found a method for staining microglia, thereby distinguishing them from other cell types (12). Microglia arise from embryonic yolk sac precursors (13), maintain their CNS population by self-renewal [microglia constitute 5-12\% of all glia cells in the adult mouse brain and $0.5-16.6 \%$ of all brain cells in the adult human brain (14)], and are not replaced by bone marrow-derived myeloid cells $(11,13)$. Previous investigators have proposed that microglia maintain their number primarily through self-renewal (15). However, recent studies have constructed a mouse model of microglial knockout by using transgenic methods and demonstrated that microglial replacement is involved with a combination of local microglial proliferation and infiltration of bone marrow-derived precursors to repopulate the niche (16). In addition, research has demonstrated that these infiltrative cells can adopt key components of the microglia transcriptome but retain large transcriptional and functional differences, even after longterm integration into the CNS (16). These findings provide a theoretical basis for the treatment of CNS diseases in the future.

Microglia eliminate microbes, dead cells, redundant synapses, protein aggregates, and other particulate and soluble antigens that may endanger the CNS. Furthermore, microglia secrete various soluble factors that contribute to different aspects of the immune response and tissue repair (17). As resident macrophages of the CNS, microglia are the first immune cells to sense ischemia and respond immediately (18). When microglia in the peri-infarct zone are activated within $30 \mathrm{~min}$ to $1 \mathrm{~h}$ after middle cerebral artery occlusion (MCAO, an experimental model of ischemic stroke), the markers CD11b, CD45, and Ibal become upregulated (19-21). This activation status of microglia after MCAO can persist for several weeks $(21,22)$. Along with the activation, some changes occur in the phenotype of microglia, which can be briefly classified into a proinflammatory or anti-inflammatory type, namely M1 or M2, respectively $(19,23,24)$. This process is called polarization of microglia, with a temporal feature that changes dynamically during the pathological process of stroke $(24,25)$. It is generally accepted that, in the acute stage (within 1 day), proliferation and activation of microglia cause a strong inflammatory reaction that is detrimental to the CNS, whereas, in the chronic stage (several days after onset), microglia can produce a variety of protective cytokines, such as neurotrophic factor IGF1, which contributes to neural repair and survival following ischemic injury (26). In addition, microglia have extensive interactions with other cells in the CNS. These facts suggest their importance and complexity in the pathogenesis of stroke. 


\section{Microglial Activation}

Microglial activation is the first step in the inflammatory response after ischemic brain injury (27). When ischemia occurs, native microglia are rapidly mobilized to the site of injury where they undergo morphological changes corresponding to the reduction of cerebral blood flow and energy deprivation (usually manifested as hypertrophy of the cell body), the development of motile branches, or migration of the somata (28-30). These morphological changes are closely associated with the function of activated microglia $(31,32)$.

Microglia are also associated with blood-brain barrier (BBB) disruption after ischemic stroke. Ischemic insults lead to junctional protein phosphorylation, translocation, or degradation, which then increase BBB permeability (33). Microglia release MMPs, such as MMP-9, which subsequently promote BBB breakdown (34). In addition, various cytokines, and chemokines produced by microglia can upregulate endothelial cell adhesion molecules and promote leukocyte infiltration (35). Neutrophils, infiltrated leukocytes, are also a major source of MMPs $(36,37)$. When reperfusion begins, activated microglia engulf endothelial cells via phagocytosis, which allows the entrance of blood serum components (38). These morphological changes are closely associated with the function of activated microglia $(31,32)$. Microglia can monitor the extracellular space and adjacent cell surfaces, and most of these can induce microglial activation. Damageassociated molecular pattern molecules (DAMPs), which include high-mobility group box 1 (HMGB1) (39), extracellular PRX family proteins $(40,41)$, and galectin-3 (42), are the main factors that activate microglia. Yenari et al. have described the signaling pathways driving microglial activation and its related transduction events (43). Several factors influence ischemia, including toll-like receptors (TLRs), particularly TLR4, HMGB1, chemokine and cytokine receptors, purinergic receptors such as $\mathrm{P} 2 \mathrm{X} 7$ and $\mathrm{P} 2 \mathrm{Y} 12$, glutamate receptors, and the triggering receptor expressed on myeloid cells 2 (TREM2). These factors are integrated through several signal transduction pathways, such as the mitogen-activated protein kinase (MAPK) cascade, NF- $\kappa b$, peroxisome proliferator activated receptor (PPAR), and others. Further studies on microglia activation signaling pathways after ischemic stroke will help to identify effective agents for suppressing microglial activation and prevent the series of microglial activation-mediated CNS injuries, including neuroinflammation.

\section{Microglial Polarization}

Polarization is a process through which macrophages adopt different phenotypes depending on the stimulus, period, and environment $(44,45)$. Like macrophages, microglia also undergo polarization. As mentioned previously, activated microglia can be defined as classic (proinflammatory; M1) or alternative (anti-inflammatory or protective; M2) under pathophysiological conditions (46).

The main basis for distinguishing between M1 and M2 microglia is their biological function as well as the secreted cytokines and chemokines. M1 microglia usually have antigenpresenting and killing effects and secrete various inflammatory factors to evoke a strong inflammatory response. Inducible nitric oxide synthase (iNOS) is a commonly used marker for M1 microglia. By contrast, M2 microglia enhance phagocytic activity to remove debris and produce many anti-inflammatory and repair factors. The enzyme arginase 1 is one of the best characterized markers of the M2 microglia (47). In vitro studies have successfully used different inducers to regulate and study the polarization of microglia; stimulation with lipopolysaccharide and interferon- $\gamma$ (IFN $\gamma$ ) promotes the differentiation of M1 microglia, whereas interleukin (IL)- 4 and IL-10 induce the M2 phenotype $(25,48-50)$. The interferon regulatory factor (IRF) family has recently been found to have an important relationship with the polarization of microglia after stroke (51-53). For example, IRF4 negatively regulates inflammation and promote M2 polarization of macrophage (54), whereas IRF5 induces M1 polarization (55). Other IRFs, such as IRF3, IRF7, and IRF8, have also been shown to participate in the process of microglial polarization. This finding opens a new perspective for stroke treatment (53).

The association between M1 and M2 differentiation and disease progression varies among different diseases. Hu et al. (25), who used a transient focal ischemia model to reveal the dynamic changes of microglial polarization, reported a differential shift from the M2 phenotype to the M1 phenotype in the ischemic brain. Specifically, soon after ischemic injury, a majority of the microglia migrated into or infiltrated infarcted areas exhibiting the M2 phenotype, which represented an endogenous effort to clear the ischemic tissue and restrict brain damage. However, the number of M2 microglia gradually decreased within 7 days, and M1 microglia consequently began to dominate the damaged area. This finding contributes to the ability to effectively determine possible intervention methods and the optimal intervention time after ischemic stroke.

In addition to classical typing, various subtypes have emerged with the deepening of microglia research. For example, M2 microglia can be further divided into three subtypes, including $\mathrm{M} 2 \mathrm{a}, \mathrm{M} 2 \mathrm{~b}$, and M2c, based on different stimulation processes and functions (56-58). Further investigation is required to explore the role of these cell populations in ischemic stroke or other CNS diseases.

Microglial polarization is theoretically greatly important in ischemic stroke; however, investigators have suggested that the M1/M2 framework is limited $(23,59)$. Ransohoff et al. (23) elaborated this perspective on microglial polarization, which is based on the current understanding of microglial polarization being influenced by macrophage polarization. This schema was adopted to simplify data interpretation at a time when the ontogeny and function of microglia had not been characterized (23). With the development of new technologies, more indepth research on microglia is expected. In this context, the significance and concept of microglial polarization also needs to be developed simultaneously.

\section{Function of Microglia in Ischemic Stroke}

Microglia activate rapidly after ischemic stroke, as described previously. However, their role is a double-edged sword because, during different periods of stroke, they have different and 
sometimes opposite functions. In the acute phase, activated microglia secrete a range of inflammatory cytokines, including tumor necrosis factor (TNF), IL-1 $\beta$, and IL-6 (60), which contribute to a robust inflammatory response. Investigators have reported that, after $\mathrm{MCAO}$, infiltrating macrophages are also a source of inflammatory factors (61). The role of macrophages and microglia in stroke is similar in many aspects and, therefore, is often described as microglia/macrophage. However, the types of major inflammatory factors produced by microglia and macrophages are different: the former produce relatively higher levels of reactive oxygen species (ROS) and TNF- $\alpha$, whereas the latter produce higher levels of IL-1 $\beta$ (61). The inflammatory response caused by the inflammatory factors secreted by these cells is a hallmark of the acute stage of ischemic stroke. It is generally believed that, in the acute phase, a severe inflammatory response like this is negatively correlated with prognosis $(62,63)$. Therefore, administering anti-inflammatory treatments in the acute stage is important.

After the acute phase of ischemic stroke, the inflammatory response gradually decreases, and ischemic stroke enters another stage during which tissue repair dominates the infarction region (64). At this stage, microglia function as a "repairer." Tissue repair after stroke relies on neurogenesis to replace injured cells. It has been suggested that microglia actively modulate neurogenesis via guiding cell migration and influencing synaptic activity by regulating the number of functional synapses in the CNS (65). It is worth noting that microglia may have a controversial effect on neurogenesis at 2 and 16 weeks after stroke. Therefore, studies with a longer observation time and multiple time points are needed to clarify when and how microglia influence neurogenesis (14).

Microglia are the major phagocytic cells in the CNS. Their phagocytosis, mediated by TREM2, CD36, and other molecules, is critical in removing degenerating neuronal cells and debris after ischemia $(66,67)$. The morphological changes in microglia within the lesion core were greater than those of microglia in the periphery, which indicated a transformation from reactive microglia to dystrophic microglia. Furthermore, reduced microglial cell numbers were in the core of the infarction, and the number of neutrophils was higher in the core than in the periphery of the lesion. These results suggest that microglia can engulf and remove neutrophils after brain ischemia, and that this phagocytic function has a distinct relationship, based on the internal location of lesions (68). The phagocytic function of microglia may also be associated with the destruction of the $\mathrm{BBB}$, which is an important pathological mechanism after ischemic stroke. Perivascular microglia can phagocytize vascular endothelial cells, thereby destroying vascular integrity after stroke (69).

\section{Microglial Interaction With Other CNS Cells}

Microglia interact with multiple cell types in the CNS and regulate numerous developmental and functional processes, including synaptic pruning and clearance of apoptotic neurons (70).

\section{Microglia and Neurons}

After ischemic stroke, neurons are the primary "victims"; they are also involved in various regulatory processes closely related to microglia. The association between microglia and neurons has been reviewed previously (14). In brief, under a pathological or physiological condition, neurons can control microglial activation via "On" and "Off" signals that are released from neurons, and neurons bind with receptors on microglia $(14,71)$.

After ischemia, microglial activation is initially triggered by neuronal death $(72,73)$. Neurons can also influence microglial function and injured neurons can stimulate microglia to exert a neuroprotective function following ischemia (14). Microglia also have diverse functions in regulating neurons. One of these is the phagocytosis of neurons. Microglial phagocytosis of neurons is regulated by neuronal presentation and microglial recognition of "eat-me" or "do-not-eat-me" signals. When microglia detect the former signals, rapid recognition and the engulfment of neurons or parts of neurons expressing such signals follow (74-76).

As previously mentioned, after cerebral ischemia, dead or degenerating neurons are engulfed by activated microglia, which is beneficial for recovery. However, existing evidence also shows that, in the ischemic penumbra where neuronal damage is reversible (77), reduced microglia phagocytosis, mediated by Mertk-deficiency or Mfge8-deficiency, helps to reduce ischemiainduced damage (78). Recent studies have also shown that, in the penumbra region, complement pathway guides phagocytosis of stressed but salvageable neurons by microglia (79). This finding provides potential therapeutic targets for future research.

Studies (80) have also observed the effects of microglia on neurons by selectively removing microglia from the brain; the results showed dysregulation of neuronal calcium responses and network activity, increased calcium accumulation, and neuronal loss after brain injury. This finding suggests that microglia promote neuronal protection. Therefore, the interaction between microglia and neurons after stroke is extensive and complex, and future research needs to focus on this interaction as well as the different functions of this interaction at different times and locations.

\section{Microglia and Astrocytes}

Both microglia and astrocytes are major components of the innate immune system in the brain. Recent studies have demonstrated the importance of microglia-astrocyte crosstalk. It was found that microglial activation can induce $\mathrm{A} 1$ reactive astrocytes in vitro and in vivo by releasing three cytokines: IL1 $\alpha$, $\mathrm{TNF} \alpha$, and the complement component subunit 1q (C1q) (81, 82). A1 astrocytes subsequently contribute to neuronal injury. Studies (83) have shown that inhibiting microglial activation and $\mathrm{M} 1$ polarization by glucagon-like peptide- 1 receptor agonists can effectively inhibit the conversion to A1 astrocytes, thereby exerting neuroprotective effects in Parkinson's disease.

In addition, recent research has found that the release of fragmented and dysfunctional microglial mitochondria is also capable of triggering the A1 astrocytic response (84). Microglial regulation of astrocytes may also involve the gut/brain axis by which microbial metabolites act directly on CNS-resident microglia and astrocytes (70). Although A1 astrocytes are 
induced by activated microglia, the cellular and molecular basis of A2 induction remain unclear (81). Future research needs to be conducted on the relationship between A2 astrocytes and microglia.

Furthermore, astrocytes also have a regulatory effect on microglia. For example, studies have demonstrated that IL-33 derived from astrocytes can serve as a rheostat, thereby helping to tune microglial synapse engulfment during neural circuit maturation and remodeling (85). However, current studies on the crosstalk between microglia and astrocytes are primarily focused on other CNS diseases. Although these studies have strong implications, future research on this complex relationship in ischemic stroke is needed.

\section{Microglia and Oligodendrocytes}

Oligodendrocytes provide axons with a myelin sheath (86), which serves a variety of functions in the brain. Investigators have found that oligodendrocytes are highly vulnerable to ischemia (87), and the disruption of the myelin architecture usually occurs after stroke (88). These injuries are closely associated with functional impairment in CNS disorders. The disruption of the ability of proliferating oligodendrocyte progenitor cells (OPCs) to mature into oligodendrocytes results in failure of remyelination, which hinders neurological recovery after stroke (88). Researchers have found that the influence of microglia on oligodendrocytes as a critical role in remyelination after stroke. Researchers have demonstrated that inflammatory factors produced by activated microglia impair oligodendrocytes/OPCs $(14,89)$. In a MCAO model, neuroinflammation mediated by TNF, MMP3, and MMP9 is an important factor in white matter damage and apoptosis of oligodendrocytes $(90,91)$. However, vascular endothelial growth factor C (VEGF-C) produced by the microglia after ischemia stimulates OPC proliferation via the VEGFR-3 receptor (92). This finding implies that microglia may have a dual role in the regulation of oligodendrocytes. Studies have also shown that the conversion of M1 microglia to the M2 phenotype is associated with remyelination. M2 microglia, which act as protector cells after stroke, can drive oligodendrocyte differentiation during remyelination, which is an essential part of an effective remyelination response (93). In fact, microglia not only have an important role in pathological conditions, but also in the homeostatic regulation of OPC during the development of CNS (94). Future research is needed to explore the specific mechanism of microglial underlying of oligodendrocytes at different stages after stroke.

\section{ASTROCYTES}

Astrocytes, which are critical components of the CNS, participate in many aspects of brain functioning, including homeostasis maintenance, synapse development, neuronal support, cerebral blood flow regulation, $\mathrm{BBB}$ formation and function, and control of neurotransmitters (95). In addition, their morphological and functional characteristics are altered under pathological conditions, a process termed as "reactive astrogliosis," and include their proliferation, the formation of a physical barrier to separate the injury site, the expression of intermediate filament proteins, cytokines, and chemokines, and regulation of the immune response (96-98). Studies indicate that astrocytes limit brain damage, reduce neuroinflammation, and are critical for $\mathrm{BBB}$ reconstruction and maintaining CNS homeostasis in the acute stages of ischemic stroke $(96,99)$. In the chronic stages, these cells facilitate and hinder functional recovery and axon regeneration. Hence, a better understanding of the mechanisms and pathways that affect astrocytes' functions may help promote the development of stroke treatment strategies.

\section{Reactive Astrocytes}

In the acute phase of stroke, injured cells in the lesion and penumbra release cytokines, including transforming growth factor (TGF)- $\alpha$, ciliary neurotrophic factor, IL-1, IL-6, and Kallikrein-related peptidase 6 (100). In response, reactive astrogliosis occurs in the peri-infarct region, and a glial scar is formed to maintain CNS homeostasis and wall off the lesion (101). The hallmarks of reactive astrogliosis are astrocytic hypertrophy and overexpression of glial fibrillary acidic protein (GFAP) (102). After undergoing reactive astrogliosis, astrocytes produce and release proinflammatory mediators, such as IL6 , TNF- $\alpha$, IL- $1 \alpha$, IL- $1 \beta$, and IFN $\gamma$, and free radicals, such as NO, superoxide, and peroxynitrite (100). By contrast, astrocyte proliferation and glial scar formation restrict the diffusion of neuroinflammation (103). Through Affymetrix GeneChip arrays, Zamanian et al. studied the expression of various genes upregulated in reactive astrocytes (104). Lcn2, which may directly promote neuronal death, was induced 228-fold, and Serpina3 $n$ was induced 9.1-fold in reactive astrocytes 1 day after experimental ischemic stroke (104). Moreover, Liddelow et al. (82) termed the two subtypes of reactive astrocytes as "A1" and "A2." They found that A1 reactive astrocytes were induced by IL- $1 \alpha$, TNF $\alpha$, and C1q secreted by activated microglia. These astrocytes have few physiological functions but contribute to the death of neurons and oligodendrocytes. One of the most upregulated genes is C3. By contrast, A2 reactive astrocytes, which upregulate neurotrophic factors, were postulated as a neuroprotective subtype. Rakers et al. (105) recently used nextgeneration sequencing to investigate transcriptome change after experimental focal ischemia. The markers of reactive astrocytes, Lcn2, Gfap, Vimentin, and Timp1, were highly expressed, as expected. The genes that contribute to inflammation (e.g., Spp1, Cd52, Lcn2, and Ifi202b), cell division, and migration (e.g., Cdk1, Myo1f, and Anxa3) were upregulated. A2-specific transcripts were intriguingly predominant at $72 \mathrm{~h}$ after tMACO (105). An in vitro study (106) showed that IL-1 $\beta$ can induce reactive astrogliosis, the upregulation of inflammatory mediators, such as IL-6 and CXCL5, and the elevation of neurotrophic factor levels, such as brain-derived neurotrophic factor and nerve growth factor. These transcriptome analyses unraveled that reactive astrocytes after ischemic stroke exerted both proinflammatory and neuroprotective functions. In addition, microglia-derived cytokines are critical for determining astrocyte phenotype.

\section{Function in the Innate Immune Response}

Astrocytes participate in innate and adaptive immune responses after ischemic stroke. Once ischemic stroke occurs, cytokines, 
DAMPs, and ROS are generated and released by injured cells to stimulate the receptors of astrocytes and alter their phenotype, thereby inducing "reactive astrogliosis." Astrocytes synthesize cytokines and chemokines and interact with other cells via the activation of their receptors and alteration of their intracellular signal pathways (Table $\mathbf{1}$ ).

The P2Y1 receptors of astrocytes that are stimulated by adenosine $5^{\prime}$-triphosphate (ATP), which is released by injured cells in post-ischemic stroke, promote the production of proinflammatory cytokines and chemokines through the phosphorylated-p65 subunit (RelA)-mediated nuclear factorkappa B (NF-кB) pathway (107). Furthermore, treatment with $\mathrm{P} 2 \mathrm{Y} 1$ receptor antagonists protects astrocytes from ischemic injury (124). Zheng et al. controversially reported that P2Y1R

TABLE 1 | Astrocyte signaling pathways in post-stroke: innate immune response.

\begin{tabular}{|c|c|c|c|}
\hline $\begin{array}{l}\text { Signaling } \\
\text { pathway }\end{array}$ & Role in neuroinflammation & Outcome & References \\
\hline \multirow[t]{2}{*}{$\begin{array}{l}\mathrm{P} 2 \mathrm{Y} 1 \\
\text { receptor }\end{array}$} & $\begin{array}{l}\text { Activates the NF-кB pathway, } \\
\text { promotes the production of } \\
\text { proinflammatory cytokines }\end{array}$ & $\begin{array}{l}\text { Increases neuronal } \\
\text { damage }\end{array}$ & (107) \\
\hline & $\begin{array}{l}\text { Regulates mitochondrial } \\
\text { metabolism }\end{array}$ & $\begin{array}{l}\text { Decreases infarct } \\
\text { volume }\end{array}$ & $(108,109)$ \\
\hline \multirow[t]{2}{*}{ TLR2/TLR4 } & $\begin{array}{l}\text { Activates JAK1/STAT1 and } \\
\text { the NF-кB pathway }\end{array}$ & $\begin{array}{l}\text { Increases neuronal } \\
\text { damage }\end{array}$ & $(110-113)$ \\
\hline & $\begin{array}{l}\text { Promotes neuroblast } \\
\text { migration and increases the } \\
\text { number of new cortical } \\
\text { neurons }\end{array}$ & $\begin{array}{l}\text { Promotes } \\
\text { neurogenesis }\end{array}$ & (114) \\
\hline CD36 & $\begin{array}{l}\text { Promotes GFAP expression; } \\
\text { Regulates proinflammatory } \\
\text { cytokines }\end{array}$ & $\begin{array}{l}\text { Reduces infract } \\
\text { volume }\end{array}$ & (115) \\
\hline TGF- $\beta$ & $\begin{array}{l}\text { Reduces infiltration of immune } \\
\text { cells }\end{array}$ & $\begin{array}{l}\text { Exerts a } \\
\text { neuroprotective } \\
\text { effect }\end{array}$ & (99) \\
\hline STAT3 & $\begin{array}{l}\text { Suppresses the production of } \\
\text { proinflammatory cytokines }\end{array}$ & $\begin{array}{l}\text { Promotes } \\
\text { neurogenesis; } \\
\text { reduces neuronal } \\
\text { damage }\end{array}$ & $(116-118)$ \\
\hline Notch1 & $\begin{array}{l}\text { Promotes reactive } \\
\text { astrogliosis; restrains } \\
\text { infiltration of immune cells }\end{array}$ & & (119) \\
\hline NF-кB & $\begin{array}{l}\text { Promotes CD11b+ leukocyte } \\
\text { infiltration; Increases the } \\
\text { production of proinflammatory } \\
\text { cytokines }\end{array}$ & $\begin{array}{l}\text { Increases neuronal } \\
\text { damage }\end{array}$ & (120) \\
\hline $\begin{array}{l}\text { TWEAK } \\
\text { Fn14 }\end{array}$ & Activates the NF-кB pathway & $\begin{array}{l}\text { Increases neuronal } \\
\text { damage }\end{array}$ & $(121,122)$ \\
\hline TIM3 & $\begin{array}{l}\text { Increases neutrophil } \\
\text { infiltration; increases neuronal } \\
\text { damage }\end{array}$ & $\begin{array}{l}\text { Increases infarct } \\
\text { volume and } \\
\text { neurological } \\
\text { deficits }\end{array}$ & (123) \\
\hline
\end{tabular}

CD11b+, cluster of differentiation 11b+; CD36, cluster of differentiation 36; Fn14, fibroblast growth factor-inducible 14; GFAP, glial fibrillary acidic protein; JAK, Janus kinase; NF-KB, nuclear factor kappa beta; STAT3, signal transducer and activator of transcription 3; TGF- $\beta$, transforming growth factor $\beta$; TIM3, T-cell immunoglobulin and mucin domaincontaining protein 3; TLR2/TLR4, toll-like receptor 2/toll-like receptor 4; TWEAK, tumor necrosis factor-like weak inducer of apoptosis. stimulation increased ATP production and decreased the infarction volume via the IP3R-dependent pathway $(108,109)$.

Toll-like receptors activated by HMGB1, PRX proteins, and other DAMPs induce the release of proinflammatory molecules (10). Among the TLR isotypes, TLR2, and TLR4 are crucial inflammatory mediators after stroke. In neurons and astrocytes, HMGB1 induces MMP-9 upregulation through activating TLR4 (125). Moreover, astrocytes treated with the TLR4 activator lipopolysaccharide upregulate the expression of SOCS-1, CXCL10, TNF- $\alpha$, VCAM-1, IL-15, and IL-27 through the MyD88-independent Jak1/Stat1 pathway and the MyD88-dependent NF- $\kappa B$ pathway (110). Suppression of TLR2 and TLR4 by pharmacological or transgenic approaches reduces NF- $\mathrm{KB}$ activity, lowering the level of proinflammatory cytokines iNOS and COX2; however, the exact mechanisms remain unclear (111-113). Growth associated protein-43 inhibits the TLR4/ NF- $\mathrm{KB}$ pathway to decrease the production of IL-6 and TNF- $\alpha$ (126). TLR4 paradoxically promotes neuroblast migration and neurogenesis after stroke (114). In addition, ischemic preconditioning stimuli ameliorate the inflammatory response after stroke via the TLR/cytokine pathway (127).

The class B scavenger receptor CD36, which is primarily found in microglia and macrophages, is co-located with GFAP in the peri-infarct astrocytes at 3-7 days after stroke (128). The ligands of CD36 produced during ischemia, such as thrombospondins, oxidized lipids, and apoptotic bodies, may upregulate its expression $(115,128)$. In addition, CD36-mediated neuroinflammation promotes the expression of intermediate filaments, free radical production, and scar formation $(115,128)$. The knockdown of CD36 reduces the level of proinflammatory factors, such as IL-1, IL-6, and MCP-1, and reduces infarct volume (115). However, the pharmacological inhibition of CD36 in hyperlipidemic stroke worsens the outcome (129). An unexpected finding is that preconditioning with a $\mathrm{CD} 36$ inhibitor can reduce the effects of stroke (129).

After ischemic stroke, TGF $\beta$ signaling is increased in astrocytes and activated microglia/macrophages after ischemic stroke (130). Studies have shown that TGF $\beta$ exerts antiapoptotic and neuroprotective effects after stroke $(131,132)$. Furthermore, the inhibition of the TGF $\beta$ pathway promotes the infiltration of immune cells in the peri-infarct lesion and does not change the physical barrier formed by astrocytes (99). To date, the exact mechanism of its neuroprotective effect is not fully elucidated. Previous studies suggest that the Smads, PI3K/Akt, ERK/MAPK, or PKA pathway could be potentially involved (99, 133-136).

The Janus kinase/signal transducer and activator of transcription 3 (JAK/STAT3) signaling pathway is one of the primary regulators affecting the functional and molecular changes in reactive astrogliosis. Reactive oxygen species and other molecules produced after ischemic stroke activate STAT3 (137). The regulation of the STAT3 pathway through miRNA31 or sinomenine attenuates neuroinflammatory and neuronal injury $(116,138)$. The increased p-STAT3 also promotes neuronal progenitor cell proliferation and functional rehabilitation via 
the STAT3-HIF1 $\alpha$-VEGF axis $(117,139)$. Investigators have postulated that IL-6 induces neuroprotection via STAT3 pathway activation $(118,140)$. The role of STAT3 signaling in ischemic stroke requires further exploration.

The Notch-1 pathway, which participates in reactive astrogliosis and neural stem cell differentiation, is activated after stroke (119). Activation of this pathway facilitates the proliferation of reactive astrocytes and restricts infiltration of immune cells (119).

NF- $\mathrm{KB}$ is another well-understood pathway that regulates proinflammatory cytokine expression. By using transgenic mice, Dvoriantchikova et al. elucidated how NF- $\mathrm{B}$ is involved in proinflammatory and redox-active pathways and has a pivotal role in neurotoxicity (120). The inhibition of the NF- $\mathrm{kB}$ pathways may reduce the expression of proinflammatory genes, including Tnf- $\alpha$, Icam1, Ccl2 (Mcp1), Cxcl10 (IP10), and Vcam1, and reduce the infiltration of CD11b+ leukocytes (120). Tumor protein 53-induced glycolysis reduces the degradation of ІкB $\alpha$ and inhibits NF- $\mathrm{KB}$ translocation in astrocytes, thereby ameliorating neuroinflammation (141).

Tumor necrosis factor-like weak inducer of apoptosis (TWEAK) and its receptor fibroblast growth factor-inducible 14 (Fn14), expressed in neurons (142), may also be a proinflammatory factor. TWEAK/Fn14 can activate NF-кB pathways and increase the expression of the chemokine monocyte chemoattractant protein-1, which leads to leukocyte infiltration into the infraction lesion (121). TWEAK stimulation also contributes to reactive astrogliosis through the TGFa/EGFR signal pathway (122). TWEAK/Fn14 inhibition therefore protects the integrity of the $\mathrm{BBB}$ and reduces infarct volume $(143,144)$. However, the TWEAK/Fn14 pathway activation in hypoxia preconditioning results in hypoxic and ischemic tolerance (145).

Hypoxia-induced glial T-cell immunoglobulin and mucin domain protein (TIM)-3 is highly expressed in astrocytes and microglia. Targeting TIM-3 for treatment decreases the infarct volume and improves neurological deficits (123).

The cytoplasmic protein, NLR family pyrin domain containing 2, which is expressed in astrocytes, forms an inflammasome with apoptosis-associated speck-like protein containing the caspase recruitment domain and caspase- 17 $(146,147)$. Its expression is significantly increased after stroke (148). In vitro, apoptosis signal-regulating kinase 1 inhibition contributes to the reduction of proinflammatory cytokines (149).

In addition to scar formation and cytokine production, astrocytes also have a beneficial role in increasing extracellular glutamate uptake and sodium/potassium-ATP activity (150), releasing neurotrophic factors (151), and rebuilding the $\mathrm{BBB}$ (152). In addition, Morizawa et al. (153) reported that some reactive astrocytes transform into phagocytic cells in the penumbra after ischemic stroke. The phagocytic markers galectin-3 and LAMP-2 increased and peaked at 7 days after stroke. The ATPbinding cassette transporter ABCA1 and its pathway molecules MEGF10 and GULP1 have a critical role in the phagocytic transformation, contributing to tissue recovery (153).

\section{Interaction With the Complement System}

The complement system, which is a major effector of the innate immune system, prevents the invasion of pathogens and regulates brain function in physiological and pathological conditions. Astrocytes express complement receptors for C1q, C3a, C5a, and CR3 (8).

C1q participates in the classical pathway of complement activation as a pattern recognition molecule. C1q secreted by microglia promotes $\mathrm{A} 1$ phenotype transformation. This process is potentially mediated by Megf10, a scavenger receptor that is predominantly expressed by astrocytes $(154,155)$. C1q deficiency is neuroprotective in neonatal mice suffering from hypoxicischemic injury (156). A Clq inhibitor reduced leukocyte infiltration and exhibited a neuroprotective effect in an adult mice ischemic injury model; unfortunately, this effect is $\mathrm{Clq}$ independent (157).

C3, a component of the complement cascade and precursor of C3a, was recently considered a marker of A1 astrocytes because of its high expression (82). Mice deficient in C3 manifested with a reduced infarction volume and decreased granulocyte infiltration (158). C3a, a derivate of C3, mediates cerebral endothelial cell activation and leukocyte recruitment (159). In previous studies, the pharmacological inhibition of the C3a-receptor promoted anti-inflammatory neuroprotection, ameliorated neurological deficits, and improved the outcome after stroke $(158,160)$. Oxygen-glucose deprivation unexpectedly increased the expression of the C3a-receptors of astrocytes in vitro, and $\mathrm{C} 3 \mathrm{a}$ administration protected astrocytes from cell death in response to ischemic stress by reducing ERK signaling and caspase-3 activation (161). This protective effect was reversed by C3a-receptor deficiency (161). Analogously, C3a expressed in astrocytes exerted a neuroprotective effect in neonatal hypoxicischemic brain injury (162). C3a overexpression or intranasal administration stimulates neural plasticity, increases the number of the new neurons in the peri-infarct area, and promotes neuronal survival $(126,163)$.

C5 apparently contributes little in the response to ischemic stroke because the infarction volume of $\mathrm{C} 5$ - deficient mice was no different from that in wildtype mice (158). However, a neuroprotective effect has been observed in C5aR1-deficient mice or in mice treated with a C5aR1 antagonist after ischemic stroke $(164,165)$.

\section{Interaction With T Cells}

Astrocytes also interact with other immune cells after stroke. Adaptive immune cells, particularly $\mathrm{T}$ cells, participate in neuroinflammation in response to ischemic stroke. Peripheral T-cell infiltration is significantly increased in the ischemic hemisphere compared with that in the contralateral hemisphere at 3 days and at 1 month after stroke (166). Most invading T cells may be a proinflammatory phenotype based on the elevated levels of activation markers, such as CD44 and CD25, and proinflammatory cytokines, such as IFN- $\gamma$, IL-17, IL-10, TNF- $\alpha$, and perforin (166).

Astrocytes can secrete IL-15, which increases the level of $\mathrm{CD} 8+\mathrm{T}$ cells and nature killer cells and promotes their function, thereby aggravating brain injury $(167,168)$. The use 
of IL-15 neutralizing antibody reduces brain damage caused by invading peripheral T cells (167). As mentioned previously, TLR4 activation by lipopolysaccharide increased the level of IL-15 (110).

In addition to $\gamma \delta \mathrm{T}$ cells, astrocytes have been reported as a partial source of IL-17, another cytokine that is assumed to be a proinflammatory factor in the acute stage of ischemic stroke (169). In addition, IL-17A interacts with TNF- $\alpha$ and leads to neutrophil invasion in vivo and the expression of other proinflammatory molecules, such as CCL20, CCL2, CXCL9, CXCL10, and CXCL11 (170, 171). Interleukin-17A-neutralizing antibody treatment improved neurological function (172). The secretion of IL-17A via the NF- $\mathrm{B}$ pathway paradoxically contributes to post-stroke neurogenesis $(173,174)$.

Treg cells accumulate after ischemic stroke (175). Astrocytes increase the level of IL-33 and CCL1 in response to stroke. IL-33 is thought to promote the proliferation of Treg cells because their numbers in the CNS after stroke is decreased in IL-33-deficient mice (175). The administration of CCL1, which binds to CCR8, increases the amount of Treg cells and promotes recovery after stroke (175). Furthermore, the level of amphiregulin (a VEGF ligand) secreted from Treg cells is elevated in the chronic stages of stroke; it regulates the IL-6 and STAT3 pathways and ameliorates neurological deficits (175). This collective evidence indicates that astrocytes promote the proliferation of Treg cells in the late phase of ischemic stroke, and that Treg cells influence neuronal recovery. However, some researchers have found that Treg cells can exacerbate brain injury by inducing BBB disruption (176).

\section{OLIGODENDROCYTES}

Oligodendrocytes, which are the primary components of the CNS, are vulnerable in acute stage ischemia and form myelin sheaths on sprouting axons in the chronic stage (177). A large number of oligodendrocytes die within $3 \mathrm{~h}$ after stroke (9). Oligodendrogenesis is a major brain repair process after ischemic stroke (177). Oligodendrocytes unfortunately do not have a selfrenewal capacity and are mostly derived from OPCs located in the corpus callosum, striatum, and the subventricular zone (86). Ischemic stroke induces OPC proliferation and migration, which contribute to the generation of mature oligodendrocytes, thereby facilitating neuronal recovery (178). In this study, we integrated oligodendrocytes and OPCs together to review their effect during post-stroke neuroinflammation (Table 2).

\section{Neuroinflammatory Influence}

After ischemic stroke, several mechanisms mediate axonal degeneration, including energy and metabolite deficiency, calcium-regulated cell apoptosis and degeneration, and myelinassociated inhibitors of regeneration (196). Oligodendrocytes undergo a complement attack and undergo apoptosis and necroptosis induced by the toxicity of the released glutamate and $\operatorname{ATP}(9,179)$. Glutamate also activates the AMPK/kainate receptors in the neighboring microglia, thereby promoting the release of proinflammatory cytokines, such as IL-1 $\beta$ and IFN$\gamma$ (179). Investigators have shown that inflammatory cytokines have a critical role in demyelination diseases. Tumor necrosis
TABLE 2 | Oligodendrocytes and oligodendrocyte progenitor cells in post-stroke neuroinflammation.

\begin{tabular}{|c|c|c|c|}
\hline & & Outcome & References \\
\hline \multirow[t]{6}{*}{$\begin{array}{l}\text { Inflammatory } \\
\text { cytokine }\end{array}$} & $\mathrm{IFN}-\gamma$ & $\begin{array}{l}\text { Induces apoptosis, delays } \\
\text { remyelination, inhibits OPC } \\
\text { proliferation and differentiation, }\end{array}$ & (179) \\
\hline & TNF- $\alpha$ & $\begin{array}{l}\text { Induces apoptosis, delays } \\
\text { remyelination }\end{array}$ & (180) \\
\hline & IL-6 & $\begin{array}{l}\text { Promotes differentiation and } \\
\text { survival }\end{array}$ & (181) \\
\hline & $\mathrm{IL}-11$ & Promotes survival & (182) \\
\hline & $\mathrm{IL}-17$ & Promotes OPC differentiation & (183) \\
\hline & $\mathrm{IL}-1 \beta$ & $\begin{array}{l}\text { Promotes the survival of } \\
\text { oligodendrocytes; } \\
\text { Promotes death of } \\
\text { oligodendrocytes and OPCs }\end{array}$ & $(179,184,185)$ \\
\hline \multirow[t]{4}{*}{$\begin{array}{l}\text { Interaction with } \\
\text { other cells }\end{array}$} & T cells & $\begin{array}{l}\text { Activates specific T cells, } \\
\text { increases infarct volume; induces } \\
\text { proliferation of OPC }\end{array}$ & $(186,187)$ \\
\hline & Neuron & $\begin{array}{l}\text { Oligodendrocytes enhance } \\
\text { axonal repair via IGF-1; } \\
\text { Suppresses axonal axonal } \\
\text { generation via Nogo-A }\end{array}$ & $(188,189)$ \\
\hline & Microglia & $\begin{array}{l}\text { Enhances oligodendrocytes } \\
\text { injury; } \\
\text { Reduces demyelination }\end{array}$ & $(190-192)$ \\
\hline & Endothelial & $\begin{array}{l}\text { Promotes OPC proliferation; } \\
\text { Oligodendrocytes regulate BBB } \\
\text { integrity. }\end{array}$ & (193-195) \\
\hline
\end{tabular}

BBB, blood-brain barrier; IFN- $\gamma$, interferon gamma; IGF-1, insulin-like growth factor-1; IL-11, interleukin 11; IL-17, interleukin 17; IL-1B, interleukin 1B; LL-6, interleukin 6; Nogo$A$, neurite outgrowth inhibitor $A ;$ OPC, oligodendrocyte progenitor cell; TNF- $\alpha$, tumor necrosis factor-alpha.

factor- $\alpha$ induces oligodendrocyte apoptosis, delays myelination, and inhibits OPC proliferation and differentiation (180). In addition, IFN- $\gamma$ induces oligodendrocyte apoptosis and reduces OPC proliferation (181). However, IL-6 combined with IL-6R enhances the differentiation and survival of oligodendrocytes (182). IL-11 promotes oligodendrocyte survival via IL-11R. IL$17 \mathrm{~A}$ also potentiates OPC differentiation through the ERK1/2 signaling pathway (183). Treatment with IL-4 promotes the regeneration and remyelination of oligodendrocytes via the IL$4 /$ PPAR $\gamma$ signaling axis (197). IL- $1 \beta$ intriguingly promotes the survival of oligodendrocytes and the death of oligodendrocytes and OPCs via the ciliary neurotrophic factor and glutamate excitotoxicity, respectively $(184,185)$. Dying oligodendrocytes release HMGB1, which combines with TLR2 and exerts autocrine trophic effects (198).

The number of OPCs increases in the penumbra after ischemic stroke but decreases in the core lesion (199). In addition, they became hypertrophic (200), with altered potassium channel permeability (201), and undergo death induced by excitotoxicity (202, 203). The overexpression of the Nertin-1 or CXCL12 gene leads to OPC migration, proliferation, and remyelination (204, 205). Furthermore, NeruoD1 expression in OPC alters their phenotype toward glutamatergic and GABAergic neurons (206). 


\section{Interaction With Other Cells}

Peripheral lymphocytes also participate in post-stroke inflammation and are interactive with OPCs and oligodendrocytes. During a stroke, BBB breakdown induces the leakage of oligodendrocyte antigens, such as myelin oligodendrocyte glycoprotein (MOG), and myelin basic protein (MBP) into the periphery (186). The immunoreactivity of MBP increases much more significantly in the core lesion than in the peri-infarct lesion (207). These antigens activate a rapid adaptive immune response (208). A previous study claimed that the activation of MBP-specific $\mathrm{T}$ cells in stroke was similar to that seen in multiple sclerosis (209). Myelin oligodendrocyte glycoprotein can could promote MOG-reactive splenocytes to infiltrate into the lesion, which increases the infarct volume and worsens the outcome (186). Jin et al. also postulated that these specific $\mathrm{T}$ cells exacerbate Th1/Th17 responses and stroke severity (187). The effect of these specific $\mathrm{T}$ cells in ischemic stroke unfortunately remains in debate (187, 210-212). Choi et al. reported that VEGF-A secreted by activated $\mathrm{T}$ cells can promote OPC proliferation through VEGFR2 activation (213). Zarriello et al. have evidenced that Tregs secrete IL-6 and fibroblast growth factor beta, and promote OPC differentiation after stroke-induced white matter injury (214). Some researchers using experimental autoimmune encephalomyelitis models have recently illustrated that OPCs can participate in neuroinflammation via LRP1 (215), and that oligodendrocytes can express antigen presenting molecules (216). This finding suggests that oligodendrocytes may be antigen-presenting cells.

That oligodendrocytes communicate with neurons via myelin-axon interactions is well-illustrated (217). The products of oligodendrocytes, such as IGF-1, a glial cellderived neurotrophic factor, enhance axonal generation (188). However, neurite outgrowth inhibitor A (also called "Nogo-A"), an inhibitory protein expressed by oligodendrocytes, suppresses axonal repair in ischemic stress (189). By contrast, neurons/axons also regulate the differentiation of OPCs through Neuregulin-1, Wnt, and Notch signaling pathways (217-219).

As shown previously, microglia are activated in response to ischemic stroke and release ROS and proinflammatory cytokines, thereby exacerbating oligodendrocyte injury; they even ingest OPCs $(190,191)$. Activated microglia subsequently

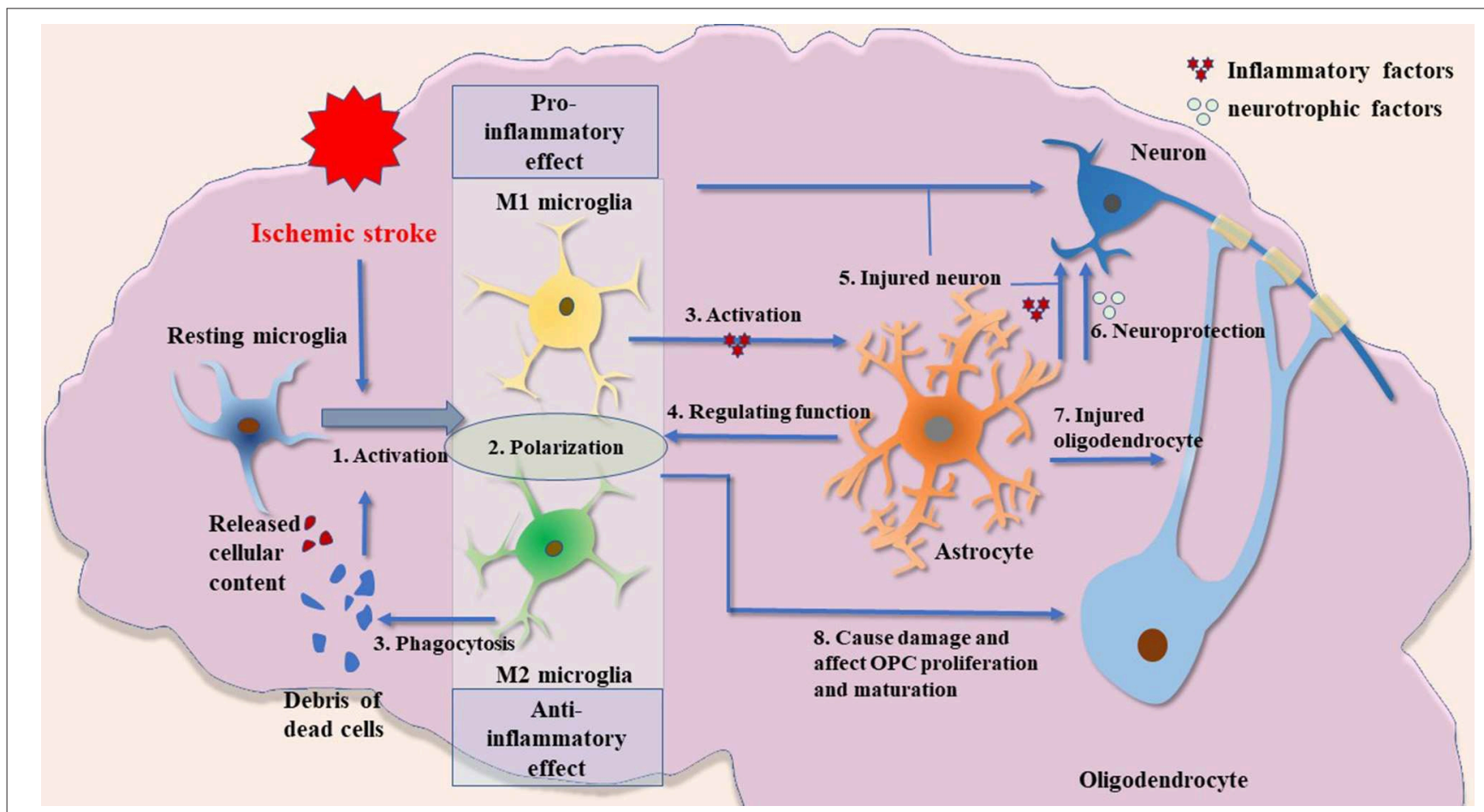

FIGURE 1 | Possible crosstalk between glial cells in ischemic stroke. (1) Microglial activation is an important process in inflammatory response after ischemic brain injury. The release of cellular contents and debris from dead cells, such as other glial cells and neurons, can cause microglial activation. These fragments will also be engulfed by microglia. (2) The M1 and M2 microglia have significantly different biological functions. In short, M1 microglia have a stronger proinflammatory phenotype, whereas M2 microglia are anti-inflammatory and have a robust function in phagocytosis. M1 and M2 microglia described in this paper are the two most widely studied types. Other types of microglia and their biological function need to be further explored. (3) Activated microglia induce the activation of astrocytes by releasing cytokines such as IL $1 \alpha$, TNF $\alpha$, and C1q. (4) Astrocytes have a regulatory effect on microglia by releasing cytokines such as IL-33. (5) Activated microglia and astrocytes can damage neurons. (6) Astrocytes may have neuroprotective functions by producing several types of neurotrophic factors. (7) Activated astrocytes have damaging effects on oligodendrocytes. (8) Microglia may have a dual role in the regulation of oligodendrocytes: inflammatory factors produced by activated microglia cause impairment of oligodendrocyte/OPCs, whereas VEGF-C produced by microglia stimulates OPC proliferation and M2 microglia can drive oligodendrocyte differentiation during remyelination. 
reduce neuroinflammation or demyelination by phagocytosis of debris (192).

Post-ischemic stroke, cerebral endothelial cells in the periinfarct lesion secrete stromal-derived factor $1 \alpha$ and VEGF, thereby promoting OPC migration (220, 221). Endothelial cells also secrete brain-derived neurotrophic factor and basic fibroblast growth factor to promote OPC proliferation (222). By contrast, oligodendrocytes enhance BBB tightness during development through TGF- $\beta$ (193). Oligodendrocyte-derived MMP-9 exerts vascular remodeling or BBB disruption effects under different conditions $(194,195)$.

\section{CONCLUSION}

Microglia are important immune cells in the CNS, and they are rapidly activated after ischemic stroke. Activated microglia were previously considered to have an adverse effect after stroke because they secrete various inflammatory cytokines (223). Inhibition of neuroinflammation by regulating the activation of microglia has long been considered an effective way to reduce stroke injuries (224). However, in addition to the detrimental effects of inflammation, microglia also exert varying neuroprotective effects after stroke, including phagocytosis of cell debris and secretion of growth factors. Further research is required to determine how these mechanisms can be applied effectively in future stroke treatment.

Microglial polarization is another important factor to consider. Further research is required to explore the mechanisms of the activation and polarization of microglia and determine how these mechanisms can be applied effectively in future stroke treatment.

Furthermore, microglia interact with most cells in the CNS, and regulate the functioning of these cells and produce a wider range of effects. Studies on these crosstalk pathways will help improve the understanding of the pathological mechanisms of stroke and other CNS diseases.

Astrocytes have also become a potential treatment target for stroke because a large number of these cells survive after stroke and exert a regulative effect in response to ischemic stroke. Antiinflammatory agents or astrocyte modulators, such as ONO256, have been investigated in previous studies (225, 226); however, none of them exhibited an advantage over the placebo. Owing to the dualistic functions of the receptors, the signaling pathways and cytokines reviewed previously, including TLR, NF$\kappa \mathrm{B}$, and others that block post-ischemic stroke inflammation,

\section{REFERENCES}

1. Cassidy JM, Cramer SC. Spontaneous and therapeutic-Induced mechanisms of functional recovery after stroke. Transl Stroke Res. (2017) 8:33-46. doi: 10.1007/s12975-016-0467-5

2. Roger VL, Go AS, Lloyd-Jones DM, Benjamin EJ, Berry JD, Borden WB, et al. Heart disease and stroke statistics-2012 update: a report from the American Heart Association. Circulation. (2012) 125:e2-220. doi: 10.1161/CIR.0b013e3182 $3 \mathrm{ac} 046$ may erase the beneficial effects. In addition, astrocytes also comprise different subsets, A1 and A2, and, after stroke, the expression of the gene characterized as A2 predominates that of A1 (105). The STAT3 pathway is also a pivotal mediator of the outcome (105). The effects of all these molecules and pathways need to be validated in future studies. Utilizing transcriptome analysis may help to determine the heterogeneity of reactive astrocytes post-stroke, understand their functions, and precisely screen for potential key regulators in neuroinflammation.

Oligodendrocytes significantly influence the recovery of patients, as they are major components of the CNS glial cells. These cytokines and intracellular signaling pathways mentioned previously regulate the migration, proliferation, and differentiation of oligodendrocytes and OPCs. Their functions could be influenced by peripheral immune cells, such as Tregs and activated $\mathrm{T}$ cells. They also interact with endothelial cells and microglia and regulate remyelination. Oligodendrocytes do not have a role as critical as that of microglia in post-stroke neuroinflammation. Therefore, finding a method to promote their survival in the acute stage poststroke and enhance axonal regeneration in the chronic stage post-stroke will be the most important targets for stroke treatment. However, based on the findings that myelin-associated proteins can activate the adaptive immune response, and antigen-specific $\mathrm{T}$ cells are a new target for therapeutics, the immune role of oligodendrocytes and OPCs post-stroke need further consideration.

In summary, the present review describes the role of glial cell activation and the involvement of immune responses mediated by them in the pathogenesis of ischemic stroke (Figure 1). This review indicates new horizons for future research such as an in-depth study of the pathological process of ischemic stroke and the exploration of potential clinical intervention targets.

\section{AUTHOR CONTRIBUTIONS}

SX, JL, and AS wrote the astrocytes, microglia, and oligodendrocytes parts respectively. JHZ and JZ revised this manuscript.

\section{FUNDING}

This work was supported by grants of the National Natural Science Fund project (87170916) to JZ.
3. Bustamante A, Simats A, Vilar-Bergua A, Garcia-Berrocoso T, Montaner J. Blood/Brain biomarkers of inflammation after stroke and their association with outcome: from c-Reactive protein to damageassociated molecular patterns. Neurotherapeutics. (2016) 13:671-84. doi: 10.1007/s13311-016-0470-2

4. Dai X, Shi X, Gao X, Liang J, Zhang XH. Salipiger nanhaiensis sp. nov., a bacterium isolated from deep sea water. Int J Syst Evol Microbiol. (2015) 65:1122-6. doi: 10.1099/ijs.0.000066

5. Iadecola C, Anrather J. The immunology of stroke: from mechanisms to translation. Nat Med. (2011) 17:796-808. doi: 10.1038/nm.2399 
6. von Bartheld CS, Bahney J, Herculano-Houzel S. The search for true numbers of neurons and glial cells in the human brain: a review of 150 years of cell counting. J Comp Neurol. (2016) 524:3865-95. doi: 10.1002/cne.24040

7. Pelvig DP, Pakkenberg H, Stark AK, Pakkenberg B. Neocortical glial cell numbers in human brains. Neurobiol Aging. (2008) 29:1754-62. doi: 10.1016/j.neurobiolaging.2007.04.013

8. Pekny M, Wilhelmsson U, Tatlisumak T, Pekna M. Astrocyte activation and reactive gliosis-a new target in stroke? Neurosci Lett. (2019) 689:45-55. doi: 10.1016/j.neulet.2018.07.021

9. Mifsud G, Zammit C, Muscat R, Di Giovanni G, Valentino M. Oligodendrocyte pathophysiology and treatment strategies in cerebral ischemia. CNS Neurosci Ther. (2014) 20:603-12. doi: 10.1111/cns.12263

10. Amantea D, Micieli G, Tassorelli C, Cuartero MI, Ballesteros I, Certo M, et al. Rational modulation of the innate immune system for neuroprotection in ischemic stroke. Front Neurosci. (2015) 9:147. doi: 10.3389/fnins.2015.00147

11. Li Q, Barres BA. Microglia and macrophages in brain homeostasis and disease. Nat Rev Immunol. (2018) 18:225-42. doi: 10.1038/nri.2017.125

12. Hickman S, Izzy S, Sen P, Morsett L, El Khoury J. Microglia in neurodegeneration. Nat Neurosci. (2018) 21:1359-69. doi: 10.1038/s41593-018-0242-x

13. Ginhoux F, Greter M, Leboeuf M, Nandi S, See P, Gokhan S, et al. Fate mapping analysis reveals that adult microglia derive from primitive macrophages. Science. (2010) 330:841-5. doi: 10.1126/science.1194637

14. Ma Y, Wang J, Wang Y, Yang GY. The biphasic function of microglia in ischemic stroke. Prog Neurobiol. (2017) 157:247-72. doi: 10.1016/j.pneurobio.2016.01.005

15. Huang Y, Xu Z, Xiong S, Sun F, Qin G, Hu G, et al. Repopulated microglia are solely derived from the proliferation of residual microglia after acute depletion. Nat Neurosci. (2018) 21:530-40. doi: 10.1038/s41593-018-0090-8

16. Lund H, Pieber M, Parsa R, Han J, Grommisch D, Ewing E, et al. Competitive repopulation of an empty microglial niche yields functionally distinct subsets of microglia-like cells. Nat Commun. (2018) 9:4845. doi: 10.1038/s41467-018-07295-7

17. Colonna M, Butovsky O. Microglia function in the central nervous system during health and neurodegeneration. Annu Rev Immunol. (2017) 35:44168. doi: 10.1146/annurev-immunol-051116-052358

18. Lambertsen KL, Finsen B, Clausen BH. Post-stroke inflammationtarget or tool for therapy? Acta Neuropathol. (2019) 137:693-714. doi: 10.1007/s00401-018-1930-z

19. Clausen BH, Lambertsen KL, Babcock AA, Holm TH, Dagnaes-Hansen F, Finsen B. Interleukin-1beta and tumor necrosis factor-alpha are expressed by different subsets of microglia and macrophages after ischemic stroke in mice. J Neuroinflam. (2008) 5:46. doi: 10.1186/1742-2094-5-46

20. Ito D, Tanaka K, Suzuki S, Dembo T, Fukuuchi Y. Enhanced expression of Ibal, ionized calcium-binding adapter molecule 1, after transient focal cerebral ischemia in rat brain. Stroke. (2001) 32:1208-15. doi: 10.1161/01.STR.32.5.1208

21. Lambertsen KL, Meldgaard M, Ladeby R, Finsen B. A quantitative study of microglial-macrophage synthesis of tumor necrosis factor during acute and late focal cerebral ischemia in mice. J Cereb Blood Flow Metab. (2005) 25:119-35. doi: 10.1038/sj.jcbfm.9600014

22. Perego C, Fumagalli S, De Simoni MG. Temporal pattern of expression and colocalization of microglia/macrophage phenotype markers following brain ischemic injury in mice. J Neuroinflam. (2011) 8:174. doi: 10.1186/1742-2094-8-174

23. Ransohoff RM. A polarizing question: do M1 and M2 microglia exist? Nat Neurosci. (2016) 19:987-91. doi: 10.1038/nn.4338

24. Tsuyama J, Nakamura A, Ooboshi H, Yoshimura A, Shichita T. Pivotal role of innate myeloid cells in cerebral post-ischemic sterile inflammation. Semin Immunopathol. (2018) 40:523-38. doi: 10.1007/s00281-018-0707-8

25. Hu X, Li P, Guo Y, Wang H, Leak RK, Chen S, et al. Microglia/macrophage polarization dynamics reveal novel mechanism of injury expansion after focal cerebral ischemia. Stroke. (2012) 43:3063-70. doi: 10.1161/STROKEAHA.112.659656

26. Lalancette-Hebert M, Gowing G, Simard A, Weng YC, Kriz J. Selective ablation of proliferating microglial cells exacerbates ischemic injury in the brain. $J$ Neurosci. (2007) 27:2596-605. doi: 10.1523/JNEUROSCI.5360-06.2007
27. Nakajima K, Kohsaka S. Microglia: neuroprotective and neurotrophic cells in the central nervous system. Curr Drug Targets Cardiovasc Haematol Disord. (2004) 4:65-84. doi: 10.2174/1568006043481284

28. Nolte C, Moller T, Walter T, Kettenmann H. Complement 5a controls motility of murine microglial cells in vitro via activation of an inhibitory G-protein and the rearrangement of the actin cytoskeleton. Neuroscience. (1996) 73:1091-107. doi: 10.1016/0306-4522(96)00106-6

29. Stence N, Waite M, Dailey ME. Dynamics of microglial activation: a confocal time-lapse analysis in hippocampal slices. Glia. (2001) 33:256-66. doi: 10.1002/1098-1136(200103)33:3<256::AID-GLIA1024>3 0.CO;2-J

30. Kreutzberg GW. Microglia: a sensor for pathological events in the CNS. Trends Neurosci. (1996) 19:312-8. doi: 10.1016/0166-2236(96)10049-7

31. Jin X, Yamashita T. Microglia in central nervous system repair after injury. $J$ Biochem. (2016) 159:491-6. doi: 10.1093/jb/mvw009

32. Walker FR, Beynon SB, Jones KA, Zhao Z, Kongsui R, Cairns M, et al. Dynamic structural remodelling of microglia in health and disease: a review of the models, the signals and the mechanisms. Brain Behav Immun. (2014) 37:1-14. doi: 10.1016/j.bbi.2013.12.010

33. Jiang X, Andjelkovic AV, Zhu L, Yang T, M.Bennett VL, Chen J, et al. Bloodbrain barrier dysfunction and recovery after ischemic stroke. Prog Neurobiol. (2018) 163-4:144-71. doi: 10.1016/j.pneurobio.2017.10.001

34. Dudvarski Stankovic N, Teodorczyk M, Ploen R, Zipp F, Schmidt MHH. Microglia-blood vessel interactions: a double-edged sword in brain pathologies. Acta Neuropathol. (2016) 131:347-63. doi: 10.1007/s00401-015-1524-y

35. da Fonseca AC, Matias D, Garcia C, Amaral R, Geraldo LH, Freitas C, et al. The impact of microglial activation on blood-brain barrier in brain diseases. Front Cell Neurosci. (2014) 8:362. doi: 10.3389/fncel.2014.00362

36. Rosell A, Ortega-Aznar A, Alvarez-Sabin J, Fernandez-Cadenas I, Ribo M, Molina CA, et al. Increased brain expression of matrix metalloproteinase-9 after ischemic and hemorrhagic human stroke. Stroke. (2006) 37:1399-406. doi: 10.1161/01.STR.0000223001.06264.af

37. Justicia C, Panes J, Sole S, Cervera A, Deulofeu R, Chamorro A, et al. Neutrophil infiltration increases matrix metalloproteinase9 in the ischemic brain after occlusion/reperfusion of the middle cerebral artery in rats. J Cereb Blood Flow Metab. (2003) 23:1430-40. doi: 10.1097/01.WCB.0000090680.07515.C8

38. Xiong XY, Liu L, Yang QW. Functions and mechanisms of microglia/macrophages in neuroinflammation and neurogenesis after stroke. Prog Neurobiol. (2016) 142:23-44. doi: 10.1016/j.pneurobio.2016.05.001

39. Yang QW, Lu FL, Zhou Y, Wang L, Zhong Q, Lin S, et al. HMBG1 mediates ischemia-reperfusion injury by TRIF-adaptor independent tolllike receptor 4 signaling. J Cereb Blood Flow Metab. (2011) 31:593-605. doi: $10.1038 /$ jcbfm.2010.129

40. Shichita T, Hasegawa E, Kimura A, Morita R, Sakaguchi R, Takada I, et al. Peroxiredoxin family proteins are key initiators of post-ischemic inflammation in the brain. Nat Med. (2012) 18:911-7. doi: 10.1038/nm.2749

41. Kunze A, Zierath D, Tanzi P, Cain K, Becker K. Peroxiredoxin 5 (PRX5) is correlated inversely to systemic markers of inflammation in acute stroke. Stroke. (2014) 45:608-10. doi: 10.1161/STROKEAHA.113.0 03813

42. Burguillos MA, Svensson M, Schulte T, Boza-Serrano A, Garcia-Quintanilla A, Kavanagh E, et al. Microglia-secreted galectin-3 acts as a toll-like receptor 4 ligand and contributes to microglial activation. Cell Rep. (2015) 10:162638. doi: 10.1016/j.celrep.2015.02.012

43. Yenari MA, Kauppinen TM, Swanson RA. Microglial activation in stroke: therapeutic targets. Neurotherapeutics. (2010) 7:378-91. doi: 10.1016/j.nurt.2010.07.005

44. Biswas SK, Mantovani A. Macrophage plasticity and interaction with lymphocyte subsets: cancer as a paradigm. Nat Immunol. (2010) 11:889-96. doi: $10.1038 /$ ni.1937

45. Gordon S, Taylor PR. Monocyte and macrophage heterogeneity. Nat Rev Immunol. (2005) 5:953-64. doi: 10.1038/nri1733

46. Kanazawa M, Ninomiya I, Hatakeyama M, Takahashi T, Shimohata T. Microglia and monocytes/Macrophages polarization reveal novel therapeutic mechanism against stroke. Int J Mol Sci. (2017) 18:E2135. doi: $10.3390 / \mathrm{ijms} 18102135$ 
47. Cherry JD, Olschowka JA, O'Banion MK. Neuroinflammation and M2 microglia: the good, the bad, and the inflamed. J Neuroinflam. (2014) 11:98. doi: 10.1186/1742-2094-11-98

48. Ding AH, Nathan CF, Stuehr DJ. Release of reactive nitrogen intermediates and reactive oxygen intermediates from mouse peritoneal macrophages. Comparison of activating cytokines and evidence for independent production. J Immunol. (1988) 141:2407-12.

49. Kigerl KA, Gensel JC, Ankeny DP, Alexander JK, Donnelly DJ, Popovich PG. Identification of two distinct macrophage subsets with divergent effects causing either neurotoxicity or regeneration in the injured mouse spinal cord. J Neurosci. (2009) 29:13435-44. doi: 10.1523/JNEUROSCI.3257-09.2009

50. Durafourt BA, Moore CS, Zammit DA, Johnson TA, Zaguia F, Guiot MC, et al. Comparison of polarization properties of human adult microglia and blood-derived macrophages. Glia. (2012) 60:717-27. doi: 10.1002/glia.22298

51. Al Mamun A, Chauhan A, Yu H, Xu Y, Sharmeen R, Liu F. Interferon regulatory factor $4 / 5$ signaling impacts on microglial activation after ischemic stroke in mice. Eur J Neurosci. (2018) 47:140-9. doi: 10.1111/ejn.13778

52. Zhao SC, Wang $\mathrm{C}, \mathrm{Xu} \mathrm{H}, \mathrm{Wu}$ WQ, Chu ZH, Ma LS, et al. Agerelated differences in interferon regulatory factor-4 and-5 signaling in ischemic brains of mice. Acta Pharmacol Sin. (2017) 38:1425-34. doi: 10.1038/aps.2017.122

53. Zhao SC, Ma LS, Chu ZH, Xu H, Wu WQ, Liu F. Regulation of microglial activation in stroke. Acta Pharmacol Sin. (2017) 38:445-58. doi: 10.1038/aps.2016.162

54. Eguchi J, Kong X, Tenta M, Wang X, Kang S, Rosen ED. Interferon regulatory factor 4 regulates obesity-induced inflammation through regulation of adipose tissue macrophage polarization. Diabetes. (2013) 62:3394-403. doi: $10.2337 / \mathrm{db} 12-1327$

55. Paun A, Reinert JT, Jiang Z, Medin C, Balkhi MY, Fitzgerald KA, et al. Functional characterization of murine interferon regulatory factor 5 (IRF-5) and its role in the innate antiviral response. J Biol Chem. (2008) 283:14295308. doi: 10.1074/jbc.M800501200

56. Chhor V, Le Charpentier T, Lebon S, Ore MV, Celador IL, JosserJ, et al. Characterization of phenotype markers and neuronotoxic potential of polarised primary microglia in vitro. Brain Behav Immun. (2013) 32:70-85. doi: 10.1016/j.bbi.2013.02.005

57. Latta CH, Sudduth TL, Weekman EM, Brothers HM, Abner EL, Popa GJ, et al. Determining the role of IL-4 induced neuroinflammation in microglial activity and amyloid-beta using BV2 microglial cells and APP/PS1 transgenic mice. J Neuroinflam. (2015) 12:41. doi: 10.1186/s12974-015-0243-6

58. Sudduth TL, Schmitt FA, Nelson PT, Wilcock DM. Neuroinflammatory phenotype in early Alzheimer's disease. Neurobiol Aging. (2013) 34:1051-9. doi: 10.1016/j.neurobiolaging.2012.09.012

59. Martinez FO, Gordon S. The M1 and M2 paradigm of macrophage activation: time for reassessment. F1000Prime Rep. (2014) 6:13. doi: 10.12703/P6-13

60. Lambertsen KL, Biber K, Finsen B. Inflammatory cytokines in experimental and human stroke. J Cereb Blood Flow Metab. (2012) 32:1677-98. doi: $10.1038 /$ jcbfm. 2012.88

61. Ritzel RM, Patel AR, Grenier JM, Crapser J, Verma R, Jellison ER, et al. Functional differences between microglia and monocytes after ischemic stroke. J Neuroinflam. (2015) 12:106. doi: 10.1186/s12974-015-0329-1

62. Chamorro A, Dirnagl U, Urra X, Planas AM. Neuroprotection in acute stroke: targeting excitotoxicity, oxidative and nitrosative stress, and inflammation. Lancet Neurol. (2016) 15:869-81. doi: 10.1016/S1474-4422(16)00114-9

63. Hankey GJ. Stroke. Lancet. (2017) 389:641-54. doi: 10.1016/S0140-6736(16)30962-X

64. Hiu T, Farzampour Z, Paz JT, Wang EH, Badgely C, Olson A, et al. Enhanced phasic GABA inhibition during the repair phase of stroke: a novel therapeutic target. Brain. (2016) 139:468-80. doi: 10.1093/brain/awv360

65. Ji K, Akgul G, Wollmuth LP, Tsirka SE. Microglia actively regulate the number of functional synapses. PLoS ONE. (2013) 8:e56293. doi: 10.1371/journal.pone.0056293
66. Woo MS, Wang X, Faustino JV, Derugin N, WendlMF, Zhou P, et al. Genetic deletion of CD36 enhances injury after acute neonatal stroke. Ann Neurol. (2012) 72:961-70. doi: 10.1002/ana.23727

67. Takahashi K, Rochford CD, Neumann H. Clearance of apoptotic neurons without inflammation by microglial triggering receptor expressed on myeloid cells-2. J Exp Med. (2005) 201:647-57. doi: 10.1084/jem. 20041611

68. Otxoa-de-Amezaga A, Miro-Mur F, Pedragosa J, Gallizioli M, Justicia C, Gaja-Capdevila N, et al. Microglial cell loss after ischemic stroke favors brain neutrophil accumulation. Acta Neuropathol. (2019) 137:321-41. doi: 10.1007/s00401-018-1954-4

69. Jolivel V, Bicker F, Biname F, Ploen R, Keller S, Gollan R, et al. Perivascular microglia promote blood vessel disintegration in the ischemic penumbra. Acta Neuropathol. (2015) 129:279-95. doi: 10.1007/s00401-014-1372-1

70. Allen NJ, Lyons DA. Glia as architects of central nervous system formation and function. Science. (2018) 362:181-5. doi: 10.1126/science.aat0473

71. Biber K, Neumann H, Inoue K, Boddeke HW. Neuronal 'On' and 'Off' signals control microglia. Trends Neurosci. (2007) 30:596-602. doi: 10.1016/j.tins.2007.08.007

72. Kriz J, Lalancette-Hebert M. Inflammation, plasticity and real-time imaging after cerebral ischemia. Acta Neuropathol. (2009) 117:497-509. doi: 10.1007/s00401-009-0496-1

73. Schwartz M. Macrophages and microglia in central nervous system injury: are they helpful or harmful? J Cereb Blood Flow Metab. (2003) 23:385-94. doi: 10.1097/01.WCB.0000061881.75234.5E

74. Brown GC, Neher JJ. Microglial phagocytosis of live neurons. Nat Rev Neurosci. (2014) 15:209-16. doi: 10.1038/nrn3710

75. Neher JJ, Neniskyte U, Zhao JW, Bal-Price A, Tolkovsky AM, Brown GC. Inhibition of microglial phagocytosis is sufficient to prevent inflammatory neuronal death. J Immunol. (2011) 186:4973-83. doi: 10.4049/jimmunol.1003600

76. Fuhrmann M, Bittner T, Jung CK, Burgold S, Page RM, Mitteregger G, et al. Microglial Cx3cr1 knockout prevents neuron loss in a mouse model of Alzheimer's disease. Nat Neurosci. (2010) 13:411-3. doi: 10.1038/nn.2511

77. Mari C, Karabiyikoglu M, Goris ML, Tait JF, Yenari MA, Blankenberg FG. Detection of focal hypoxic-ischemic injury and neuronal stress in a rodent model of unilateral MCA occlusion/reperfusion using radiolabeled annexin V. Eur J Nucl Med Mol Imag. (2004) 31:733-9. doi: 10.1007/s00259-004-1473-5

78. Neher JJ, Emmrich JV, Fricker M, Mander PK, Thery C, Brown GC. Phagocytosis executes delayed neuronal death after focal brain ischemia. Proc Natl Acad Sci USA. (2013) 110:E4098-107. doi: 10.1073/pnas.1308679110

79. Alawieh A, Langley EF, Tomlinson S. Targeted complement inhibition salvages stressed neurons and inhibits neuroinflammation after stroke in mice. Sci Transl Med. (2018) 10:eaao6459. doi: 10.1126/scitranslmed.aao6459

80. Szalay G, Martinecz B, Lenart N, Kornyei Z, Orsolits B, Judak L, et al. Microglia protect against brain injury and their selective elimination dysregulates neuronal network activity after stroke. Nat Commun. (2016) 7:11499. doi: $10.1038 /$ ncomms11499

81. Liddelow SA, Barres BA. Reactive astrocytes: production, function, and therapeutic potential. Immunity. (2017) 46:957-67. doi: 10.1016/j.immuni.2017.06.006

82. Liddelow SA, Guttenplan KA, Clarke LE, Bennett FC, Bohlen CJ, Schirmer $\mathrm{L}$, et al. Neurotoxic reactive astrocytes are induced by activated microglia. Nature. (2017) 541:481-7. doi: 10.1038/nature21029

83. Yun SP, Kam TI, Panicker N, Kim S, Oh Y, Park JS, et al. Block of A1 astrocyte conversion by microglia is neuroprotective in models of Parkinson's disease. Nat Med. (2018) 24:931-8. doi: 10.1038/s41591-018-0051-5

84. Joshi AU, Minhas PS, Liddelow SA, Haileselassie B, Andreasson KI, Dorn GW, et al. Fragmented mitochondria released from microglia trigger A1 astrocytic response and propagate inflammatory neurodegeneration. Nat Neurosci. (2019) 22:1635-48. doi: 10.1038/s41593-019-0486-0

85. Vainchtein ID, Chin G, Cho FS, Kelley KW, Miller JG, Chien EC, et al. Astrocyte-derived interleukin-33 promotes microglial synapse engulfment and neural circuit development. Science. (2018) 359:1269-73. doi: $10.1126 /$ science.aal3589 
86. McTigue DM, Tripathi RB. The life, death, and replacement of oligodendrocytes in the adult CNS. J Neurochem. (2008) 107:1-19. doi: 10.1111/j.1471-4159.2008.05570.x

87. Back SA. White matter injury in the preterm infant: pathology and mechanisms. Acta Neuropathol. (2017) 134:331-49. doi: 10.1007/s00401-017-1718-6

88. Marin MA, Carmichael ST. Mechanisms of demyelination and remyelination in the young and aged brain following white matter stroke. Neurobiol Dis. (2019) 126:5-12. doi: 10.1016/j.nbd.2018.07.023

89. Deng Y, Lu J, Sivakumar V, Ling EA, Kaur C. Amoeboid microglia in the periventricular white matter induce oligodendrocyte damage through expression of proinflammatory cytokines via MAP kinase signaling pathway in hypoxic neonatal rats. Brain Pathol. (2008) 18:387-400. doi: 10.1111/j.1750-3639.2008.00138.x

90. Jalal FY, Yang Y, Thompson J, Lopez AC, Rosenberg GA. Myelin loss associated with neuroinflammation in hypertensive rats. Stroke. (2012) 43:1115-22. doi: 10.1161/STROKEAHA.111.643080

91. Yang Y, Jalal FY, Thompson JF, Walker EJ, Candelario-Jalil E, Li L, et al. Tissue inhibitor of metalloproteinases-3 mediates the death of immature oligodendrocytes via TNF-alpha/TACE in focal cerebral ischemia in mice. J Neuroinflammation. (2011) 8:108. doi: 10.1186/1742-2094-8-108

92. Bain JM, Moore L, Ren Z, Simonishvili S, Levison SW. Vascular endothelial growth factors $\mathrm{A}$ and $\mathrm{C}$ are induced in the SVZ following neonatal hypoxiaischemia and exert different effects on neonatal glial progenitors. Transl Stroke Res. (2013) 4:158-70. doi: 10.1007/s12975-012-0213-6

93. Miron VE, Boyd A, Zhao JW, Yuen TJ, Ruckh JM, Shadrach JL, et al. M2 microglia and macrophages drive oligodendrocyte differentiation during CNS remyelination. Nat Neurosci. (2013) 16:1211-18. doi: 10.1038/nn.3469

94. Hagemeyer N, Hanft KM, Akriditou MA, Unger N, Park ES, Stanley ER, et al. Microglia contribute to normal myelinogenesis and to oligodendrocyte progenitor maintenance during adulthood. Acta Neuropathol. (2017) 134:441-58. doi: 10.1007/s00401-017-1747-1

95. Jha MK, Kim JH, Song GJ, Lee WH, Lee IK, Lee HW, et al. Functional dissection of astrocyte-secreted proteins: implications in brain health and diseases. Prog Neurobiol. (2018) 162:37-69. doi: 10.1016/j.pneurobio.2017.12.003

96. Li L, Lundkvist A, Andersson D, Wilhelmsson U, Nagai N, Pardo AC, et al. Protective role of reactive astrocytes in brain ischemia. J Cereb Blood Flow Metab. (2008) 28:468-81. doi: 10.1038/sj.jcbfm.9600546

97. Pekny M, Pekna M, Messing A, Steinhauser C, Lee JM, Parpura V, et al. Astrocytes: a central element in neurological diseases. Acta Neuropathol. (2016) 131:323-45. doi: 10.1007/s00401-015-1513-1

98. Cekanaviciute E, Buckwalter MS. Astrocytes: integrative regulators of neuroinflammation in stroke and other neurological diseases. Neurotherapeutics. (2016) 13:685-701. doi: 10.1007/s13311-016-0477-8

99. Cekanaviciute E, Fathali N, Doyle KP, Williams AM, Han J, Buckwalter MS. Astrocytic transforming growth factor-beta signaling reduces subacute neuroinflammation after stroke in mice. Glia. (2014) 62:1227-40. doi: 10.1002/glia.22675

100. Liu Z, Chopp M. Astrocytes, therapeutic targets for neuroprotection and neurorestoration in ischemic stroke. Prog Neurobiol. (2016) 144:103-20. doi: $10.1016 /$ j.pneurobio.2015.09.008

101. Choudhury GR, Ding S. Reactive astrocytes and therapeutic potential in focal ischemic stroke. Neurobiol Dis. (2016) 85:234-44. doi: 10.1016/j.nbd.2015.05.003

102. Ben Haim L, Carrillo-de Sauvage MA, Ceyzeriat K, Escartin C. Elusive roles for reactive astrocytes in neurodegenerative diseases. Front Cell Neurosci. (2015) 9:278. doi: 10.3389/fncel.2015.00278

103. Sofroniew MV. Reactive astrocytes in neural repair and protection. Neuroscientist. (2005) 11:400-7. doi: 10.1177/1073858405278321

104. Zamanian JL, Xu L, Foo LC, Nouri N, Zhou L, Giffard RG, et al. Genomic analysis of reactive astrogliosis. J Neurosci. (2012) 32:6391-410. doi: 10.1523/JNEUROSCI.6221-11.2012

105. Rakers C, Schleif M, Blank N, Matuskova H, Ulas T, Handler K, et al. Stroke target identification guided by astrocyte transcriptome analysis. Glia. (2019) 67:619-33. doi: 10.1002/glia.23544

106. Teh DBL, Prasad A, Jiang W, Ariffin MZ, Khanna S, Belorkar A, et al. Transcriptome analysis reveals neuroprotective aspects of human reactive astrocytes induced by interleukin 1beta. Sci Rep. (2017) 7:13988 doi: 10.1038/s41598-017-13174-w

107. Kuboyama K, Harada H, Tozaki-Saitoh H, Tsuda M, Ushijima K, Inoue K. Astrocytic P2Y(1) receptor is involved in the regulation of cytokine/chemokine transcription and cerebral damage in a rat model of cerebral ischemia. J Cereb Blood Flow Metab. (2011) 31:1930-41. doi: $10.1038 / j \mathrm{jbfm} .2011 .49$

108. Zheng W, Talley Watts L, Holstein DM, Wewer J, Lechleiter JD. P2Y1Rinitiated, IP3R-dependent stimulation of astrocyte mitochondrial metabolism reduces and partially reverses ischemic neuronal damage in mouse. J Cereb Blood Flow Metab. (2013) 33:600-11. doi: $10.1038 /$ jcbfm. 2012.214

109. Zheng W, Watts LT, Holstein DM, Prajapati SI, Keller C, Grass EH, et al. Purinergic receptor stimulation reduces cytotoxic edema and brain infarcts in mouse induced by photothrombosis by energizing glial mitochondria. PLoS ONE. (2010) 5:e14401. doi: 10.1371/journal.pone.0014401

110. Gorina R, Font-Nieves M, Marquez-Kisinousky L, Santalucia T, Planas AM. Astrocyte TLR4 activation induces a proinflammatory environment through the interplay between MyD88-dependent NFkappaB signaling, MAPK, and Jak1/Stat1 pathways. Glia. (2011) 59:242-55. doi: 10.1002/glia.21094

111. Cao CX, Yang QW, Lv FL, Cui J, Fu HB, Wang JZ. Reduced cerebral ischemia-reperfusion injury in toll-like receptor 4 deficient mice. Biochem Biophys Res Commun. (2007) 353:509-14. doi: 10.1016/j.bbrc.2006.12.057

112. Hyakkoku K, Hamanaka J, Tsuruma K, Shimazawa M, Tanaka H, Uematsu S, et al. Toll-like receptor 4 (TLR4), but not TLR3 or TLR9, knock-out mice have neuroprotective effects against focal cerebral ischemia. Neuroscience. (2010) 171:258-67. doi: 10.1016/j.neuroscience.2010.08.054

113. Tang SC, Arumugam TV, Xu X, Cheng A, Mughal MR, Jo DG, et al. Pivotal role for neuronal toll-like receptors in ischemic brain injury and functional deficits. Proc Natl Acad Sci USA. (2007) 104:13798-803. doi: 10.1073/pnas.0702553104

114. Moraga A, Pradillo JM, Cuartero MI, Hernandez-Jimenez M, Oses M, Moro MA, et al. Toll-like receptor 4 modulates cell migration and cortical neurogenesis after focal cerebral ischemia. FASEB J. (2014) 28:4710-8. doi: 10.1096/fj.14-252452

115. Bao Y, Qin L, Kim E, Bhosle S, Guo H, Febbraio M, et al. CD36 is involved in astrocyte activation and astroglial scar formation. J Cereb Blood Flow Metab. (2012) 32:1567-77. doi: 10.1038/jcbfm.2012.52

116. Qiu J, Yan Z, Tao K, Li Y, Li Y, Li J, et al. Sinomenine activates astrocytic dopamine D2 receptors and alleviates neuroinflammatory injury via the CRYAB/STAT3 pathway after ischemic stroke in mice. J Neuroinflam. (2016) 13:263. doi: 10.1186/s12974-016-0739-8

117. Wu X, Liu S, Hu Z, Zhu G, Zheng G, Wang G. Enriched housing promotes post-stroke neurogenesis through calpain 1STAT3/HIF-1alpha/VEGF signaling. Brain Res Bull. (2018) 139:133-43. doi: 10.1016/j.brainresbull.2018.02.018

118. Jung JE, Kim GS, Chan PH. Neuroprotection by interleukin-6 is mediated by signal transducer and activator of transcription 3 and antioxidative signaling in ischemic stroke. Stroke. (2011) 42:3574-9. doi: 10.1161/STROKEAHA.111.626648

119. Shimada IS, Borders A, Aronshtam A, Spees JL. Proliferating reactive astrocytes are regulated by Notch-1 in the peri-infarct area after stroke. Stroke. (2011) 42:3231-7. doi: 10.1161/STROKEAHA.111.6 23280

120. Dvoriantchikova G, Barakat D, Brambilla R, Agudelo C, Hernandez E, Bethea JR, et al. Inactivation of astroglial NF-kappa B promotes survival of retinal neurons following ischemic injury. Eur J Neurosci. (2009) 30:175-85 doi: 10.1111/j.1460-9568.2009.06814.x

121. Haile WB, Echeverry R, Wu J, Yepes M. The interaction between tumor necrosis factor-like weak inducer of apoptosis and its receptor fibroblast growth factor-inducible 14 promotes the recruitment of neutrophils into the ischemic brain. J Cereb Blood Flow Metab. (2010) 30:1147-56 doi: $10.1038 /$ jcbfm. 2009.280

122. Rousselet E, Traver S, Monnet Y, Perrin A, Mandjee N, Hild A, et al. Tumor necrosis factor-like weak inducer of apoptosis induces astrocyte proliferation through the activation of transforming-growth factor-alpha/epidermal growth factor receptor signaling pathway. Mol Pharmacol. (2012) 82:948-57. doi: $10.1124 / \mathrm{mol} .112 .079608$ 
123. Koh HS, Chang CY, Jeon SB, Yoon HJ, Ahn YH, Kim HS, et al. The HIF1/glial TIM-3 axis controls inflammation-associated brain damage under hypoxia. Nat Commun. (2015) 6:6340. doi: 10.1038/ncomms7340

124. Guo H, Liu ZQ, Zhou H, Wang ZL, Tao YH, Tong Y. P2Y1 receptor antagonists mitigate oxygen and glucose deprivation induced astrocyte injury. Mol Med Rep. (2018) 17:1819-24. doi: 10.3892/mmr.2017. 8072

125. Qiu J, Xu J, Zheng Y, Wei Y, Zhu X, Lo EH, et al. High-mobility group box 1 promotes metalloproteinase-9 upregulation through tolllike receptor 4 after cerebral ischemia. Stroke. (2010) 41:2077-82. doi: 10.1161/STROKEAHA.110.590463

126. Hung $\mathrm{CC}$, Lin $\mathrm{CH}$, Chang $\mathrm{H}$, Wang $\mathrm{CY}$, Lin $\mathrm{SH}$, Hsu $\mathrm{PC}$, et al. Astrocytic GAP43 induced by the TLR4/NF-kappaB/STAT3 axis attenuates astrogliosis-mediated microglial activation and neurotoxicity. J Neurosci. (2016) 36:2027-43. doi: 10.1523/JNEUROSCI.3457-15.2016

127. Kariko K, Weissman D, Welsh FA. Inhibition of toll-like receptor and cytokine signaling-a unifying theme in ischemic tolerance. J Cereb Blood Flow Metab. (2004) 24:1288-304. doi: 10.1097/01.WCB.0000145666.68576.71

128. Cho S, Park EM, Febbraio M, Anrather J, Park L, Racchumi G, et al. The class B scavenger receptor CD36 mediates free radical production and tissue injury in cerebral ischemia. J Neurosci. (2005) 25:2504-12. doi: 10.1523/JNEUROSCI.0035-05.2005

129. Kim E, Yang J, Woo Park K, Cho S. Preventative, but not poststroke, inhibition of CD36 attenuates brain swelling in hyperlipidemic stroke. J Cereb Blood Flow Metab. (2019) 15:271678x19850004. doi: $10.1177 / 0271678 X 19850004$

130. Doyle KP, Cekanaviciute E, Mamer LE, Buckwalter MS. TGF $\beta$ signaling in the brain increases with aging and signals to astrocytes and innate immune cells in the weeks after stroke. J Neuroinflam. (2010) 7:62. doi: 10.1186/1742-2094-7-62

131. Ruocco A, Nicole O, Docagne F, Ali C, Chazalviel L, Komesli S, et al. A transforming growth factor-beta antagonist unmasks the neuroprotective role of this endogenous cytokine in excitotoxic and ischemic brain injury. J Cereb Blood Flow Metab. (1999) 19:1345-53. doi: 10.1097/00004647-199912000-00008

132. Pang L, Ye W, Che XM, Roessler BJ, Betz AL, Yang GY. Reduction of inflammatory response in the mouse brain with adenoviral-mediated transforming growth factor-ss1 expression. Stroke. (2001) 32:544-52. doi: 10.1161/01.STR.32.2.544

133. Cho ML, Min SY, Chang SH, Kim KW, Heo SB, Lee SH, et al. Transforming growth factor beta 1(TGF-beta1) down-regulates TNFalphainduced RANTES production in rheumatoid synovial fibroblasts through NF-kappaB-mediated transcriptional repression. Immunol Lett. (2006) 105:159-66. doi: 10.1016/j.imlet.2006.02.003

134. Zhang YE. Non-Smad signaling pathways of the TGF-beta family. Cold Spring Harb Perspect Biol. (2017) 9:a022129. doi: 10.1101/cshperspect.a022129

135. Zhu Y, Yang GY, Ahlemeyer B, Pang L, Che XM, Culmsee C, et al. Transforming growth factor-beta 1 increases bad phosphorylation and protects neurons against damage. J Neurosci. (2002) 22:3898-909. doi: 10.1523/JNEUROSCI.22-10-03898.2002

136. Zhang R, Wu Y, Xie F, Zhong Y, Wang Y, Xu M, et al. RGMa mediates reactive astrogliosis and glial scar formation through TGFbeta1/Smad2/3 signaling after stroke. Cell Death Differ. (2018) 25:1503-16. doi: 10.1038/s41418-018-0058-y

137. Lei C, Deng J, Wang B, Cheng D, Yang Q, Dong H, et al. Reactive oxygen species scavenger inhibits STAT3 activation after transient focal cerebral ischemia-reperfusion injury in rats. Anesth Analg. (2011) 113:153-9. doi: 10.1213/ANE.0b013e31821a9fbe

138. Li J, Lv H, Che YQ. Upregulated microRNA-31 inhibits oxidative stressinduced neuronal injury through the JAK/STAT3 pathway by binding to PKD1 in mice with ischemic stroke. J Cell Physiol. (2019) 235:2414-28. doi: $10.1002 /$ jcp. 29146

139. Zhu H, Zou L, Tian J, Du G, Gao Y. SMND-309, a novel derivative of salvianolic acid B, protects rat brains ischemia and reperfusion injury by targeting the JAK2/STAT3 pathway. Eur J Pharmacol. (2013) 714:23-31. doi: 10.1016/j.ejphar.2013.05.043
140. Yamashita T, Sawamoto K, Suzuki S, Suzuki N, Adachi K, Kawase T, et al. Blockade of interleukin-6 signaling aggravates ischemic cerebral damage in mice: possible involvement of Stat3 activation in the protection of neurons. J Neurochem. (2005) 94:459-68. doi: 10.1111/j.1471-4159.2005. 03227.x

141. Chen J, Zhang DM, Feng X, Wang J, Qin YY, Zhang T, et al. TIGAR inhibits ischemia/reperfusion-induced inflammatory response of astrocytes. Neuropharmacology. (2018) 131:377-88. doi: 10.1016/j.neuropharm.2018.01.012

142. Haile WB, Echeverry R, Wu F, Guzman J, An J, Wu J, et al. Tumor necrosis factor-like weak inducer of apoptosis and fibroblast growth factor-inducible 14 mediate cerebral ischemia-induced poly(ADP-ribose) polymerase-1 activation and neuronal death. Neuroscience. (2010) 171:1256-64. doi: 10.1016/j.neuroscience.2010. 10.029

143. Zhang X, Winkles JA, Gongora MC, Polavarapu R, Michaelson JS, Hahm $\mathrm{K}$, et al. TWEAK-Fn14 pathway inhibition protects the integrity of the neurovascular unit during cerebral ischemia. J Cereb Blood Flow Metab. (2007) 27:534-44. doi: 10.1038/sj.jcbfm.9600368

144. Yepes M, Brown SA, Moore EG, Smith EP, Lawrence DA, Winkles JA. A soluble Fn14-Fc decoy receptor reduces infarct volume in a murine model of cerebral ischemia. Am J Pathol. (2005) 166:511-20. doi: 10.1016/S0002-9440(10)62273-0

145. Echeverry R, Wu F, Haile WB, Wu J, Yepes M. The cytokine tumor necrosis factor-like weak inducer of apoptosis and its receptor fibroblast growth factor-inducible 14 have a neuroprotective effect in the central nervous system. J Neuroinflammation. (2012) 9:45. doi: 10.1186/1742-2094-9-45

146. de Rivero Vaccari, JP, Dietrich WD, Keane RW. Activation and regulation of cellular inflammasomes: gaps in our knowledge for central nervous system injury. J Cereb Blood Flow Metab. (2014) 34:369-75. doi: $10.1038 /$ jcbfm.2013.227

147. Minkiewicz J, de Rivero Vaccari JP, Keane RW. Human astrocytes express a novel NLRP2 inflammasome. Glia. (2013) 61:1113-21. doi: 10.1002/glia.22499

148. Sun X, Song X, Zhang L, Sun J, Wei X, Meng L, et al. NLRP2 is highly expressed in a mouse model of ischemic stroke. Biochem Biophys Res Commun. (2016) 479:656-62. doi: 10.1016/j.bbrc.2016. 09.157

149. Cheon SY, Kim EJ, Kim SY, Kim JM, Kam EH, Park JK, et al. Apoptosis signal-regulating kinase 1 silencing on astroglial inflammasomes in an experimental model of ischemic stroke. Neuroscience. (2018) 390:218-30. doi: 10.1016/j.neuroscience.2018.08.020

150. Stanimirovic DB, Ball R, Durkin JP. Stimulation of glutamate uptake and Na,K-ATPase activity in rat astrocytes exposed to ischemia-like insults. Glia. (1997) 19:123-34. doi: 10.1002/(sici) 1098-1136(199702)19:2<123::aid-glia4>3.0.co;2-1

151. Barreto G, White RE, Ouyang Y, Xu L, Giffard RG. Astrocytes: targets for neuroprotection in stroke. Cent Nerv Syst Agents Med Chem. (2011) 11:164-73. doi: 10.2174/187152411796011303

152. del Zoppo GJ. Inflammation and the neurovascular unit in the setting of focal cerebral ischemia. Neuroscience. (2009) 158:972-82. doi: 10.1016/j.neuroscience.2008.08.028

153. Morizawa YM, Hirayama Y, Ohno N, Shibata S, Shigetomi E, Sui $\mathrm{Y}$, et al. Reactive astrocytes function as phagocytes after brain ischemia via ABCA1-mediated pathway. Nat Commun. (2017) 8:28. doi: 10.1038/s41467-017-01594-1

154. Zhang Y, Chen K, Sloan SA, Bennett ML, Scholze AR, O'Keeffe S, et al. An RNA-sequencing transcriptome and splicing database of glia, neurons, and vascular cells of the cerebral cortex. J Neurosci. (2014) 34:11929-47. doi: 10.1523/JNEUROSCI.1860-14.2014

155. Iram $\mathrm{T}$, Ramirez-Ortiz Z, Byrne $\mathrm{MH}$, Coleman UA, Kingery ND, Means TK, et al. Megf10 is a receptor for C1Q that mediates clearance of apoptotic cells by astrocytes. J Neurosci. (2016) 36:5185-92. doi: 10.1523/JNEUROSCI.3850-15.2016

156. Ten VS, Sosunov SA, Mazer SP, Stark RI, Caspersen C, Sughrue $\mathrm{ME}$, et al. C1q-deficiency is neuroprotective against hypoxicischemic brain injury in neonatal mice. Stroke. (2005) 36:2244-50. doi: $10.1161 / 01 . S T R .0000182237 .20807 . d 0$ 
157. De Simoni MG, Rossi E, Storini C, Pizzimenti S, Echart C, Bergamaschini $\mathrm{L}$. The powerful neuroprotective action of C1-inhibitor on brain ischemiareperfusion injury does not require C1q. Am J Pathol. (2004) 164:1857-63. doi: 10.1016/S0002-9440(10)63744-3

158. Mocco J, Mack WJ, Ducruet AF, Sosunov SA, Sughrue ME, Hassid BG, et al. Complement component C3 mediates inflammatory injury following focal cerebral ischemia. Circ Res. (2006) 99:209-17. doi: 10.1161/01.RES.0000232544.90675.42

159. Wu F, Zou Q, Ding X, Shi D, Zhu X, Hu W, et al. Complement component C3a plays a critical role in endothelial activation and leukocyte recruitment into the brain. J Neuroinflam. (2016) 13:23. doi: 10.1186/s12974-0160485-y

160. Ducruet AF, Zacharia BE, Sosunov SA, Gigante PR, Yeh ML, Gorski JW, et al. Complement inhibition promotes endogenous neurogenesis and sustained anti-inflammatory neuroprotection following reperfused stroke. PLOS ONE. (2012) 7:e38664. doi: 10.1371/journal.pone.0038664

161. Shinjyo N, de Pablo Y, Pekny M, Pekna M. Complement peptide C3a promotes astrocyte survival in response to ischemic stress. Mol Neurobiol. (2016) 53:3076-87. doi: 10.1007/s12035-015-9204-4

162. Jarlestedt K, Rousset CI, Stahlberg A, Sourkova H, Atkins AL, Thornton $\mathrm{C}$, et al. Receptor for complement peptide C3a: a therapeutic target for neonatal hypoxic-ischemic brain injury. FASEB J. (2013) 27:3797-804. doi: 10.1096/fj.13-230011

163. Stokowska A, Atkins AL, Moran J, Pekny T, Bulmer L, Pascoe MC, et al. Complement peptide C3a stimulates neural plasticity after experimental brain ischaemia. Brain. (2017) 140:353-69. doi: 10.1093/brain/aww314

164. Pavlovski D, Thundyil J, Monk PN, Wetsel RA, Taylor SM, Woodruff TM. Generation of complement component C5a by ischemic neurons promotes neuronal apoptosis. FASEB J. (2012) 26:3680-90. doi: 10.1096/fj.11-202382

165. Kim GH, Mocco J, Hahn DK, Kellner CP, Komotar RJ, Ducruet AF, et al. Protective effect of $\mathrm{C} 5$ a receptor inhibition after murine reperfused stroke. Neurosurgery. (2008) 63:122-5. doi: 10.1227/01.NEU.0000335079.70222.8D

166. Xie L, Li W, Hersh J, Liu R, Yang SH. Experimental ischemic stroke induces long-term T cell activation in the brain. J Cereb Blood Flow Metab. (2018) 39:2268-76. doi: 10.1177/0271678X18792372

167. Lee GA, Lin TN, Chen CY, Mau SY, Huang WZ, Kao YC, et al. Interleukin 15 blockade protects the brain from cerebral ischemia-reperfusion injury. Brain Behav Immun. (2018) 73:562-70. doi: 10.1016/j.bbi.2018.06.021

168. Li M, Li Z, Yao Y, Jin WN, Wood K, Liu Q, et al. Astrocytederived interleukin-15 exacerbates ischemic brain injury via propagation of cellular immunity. Proc Natl Acad Sci USA. (2017) 114:E396-405. doi: 10.1073/pnas.1612930114

169. Li GZ, Zhong D, Yang LM, Sun B, Zhong ZH, Yin YH, et al. Expression of interleukin-17 in ischemic brain tissue. Scand J Immunol. (2005) 62:481-6. doi: $10.1111 / j .1365-3083.2005 .01683 . x$

170. Gelderblom M, Weymar A, Bernreuther C, Velden J, Arunachalam P, Steinbach K, et al. Neutralization of the IL-17 axis diminishes neutrophil invasion and protects from ischemic stroke. Blood. (2012) 120:3793-802. doi: 10.1182/blood-2012-02-412726

171. Kang Z, Altuntas CZ, Gulen MF, Liu C, Giltiay N, Qin H, et al. Astrocyterestricted ablation of interleukin-17-induced Act1-mediated signaling ameliorates autoimmune encephalomyelitis. Immunity. (2010) 32:414-25. doi: 10.1016/j.immuni.2010.03.004

172. Dai Q, Li S, Liu T, Zheng J, Han S, Qu A, et al. Interleukin-17A-mediated alleviation of cortical astrocyte ischemic injuries affected the neurological outcome of mice with ischemic stroke. J Cell Biochem. (2019) 120:11498-509. doi: $10.1002 /$ jcb. 28429

173. Zhang Y, Xu D, Qi H, Yuan Y, Liu H, Yao S, et al. Enriched environment promotes post-stroke neurogenesis through NF-kappaBmediated secretion of IL-17A from astrocytes. Brain Res. (2018) 1687:20-31. doi: 10.1016/j.brainres.2018.02.030

174. Lin Y, Zhang JC, Yao CY, Wu Y, Abdelgawad AF, Yao SL, et al. Critical role of astrocytic interleukin-17 A in post-stroke survival and neuronal differentiation of neural precursor cells in adult mice. Cell Death Dis. (2016) 7:e2273. doi: $10.1038 /$ cddis.2015.284

175. Ito M, Komai K, Mise-Omata S, Iizuka-Koga M, Noguchi Y, Kondo T, et al. Brain regulatory $\mathrm{T}$ cells suppress astrogliosis and potentiate neurological recovery. Nature. (2019) 565:246-50. doi: 10.1038/s41586-018-0824-5
176. Kleinschnitz C, Kraft P, Dreykluft A, Hagedorn I, Gobel K, Schuhmann MK et al. Regulatory $\mathrm{t}$ cells are strong promoters of acute ischemic stroke in mice by inducing dysfunction of the cerebral microvasculature. Blood. (2013) 121:679-91. doi: 10.1182/blood-2012-04-426734

177. Zhang ZG, Chopp M. Neurorestorative therapies for stroke: underlying mechanisms and translation to the clinic. Lancet Neurol. (2009) 8:491-500. doi: 10.1016/S1474-4422(09)70061-4

178. Zhang R, Chopp M, Zhang ZG. Oligodendrogenesis after cerebral ischemia. Front Cell Neurosci. (2013) 7:201. doi: 10.3389/fncel.2013.00201

179. Alberdi E, Sanchez-Gomez MV, Torre I, Domercq M, Perez-Samartin A, Perez-Cerda F, et al. Activation of kainate receptors sensitizes oligodendrocytes to complement attack. J Neurosci. (2006) 26:3220-8. doi: 10.1523/JNEUROSCI.3780-05.2006

180. Shi H, Hu X, Leak RK, Shi Y, An C, Suenaga J, et al. Demyelination as a rational therapeutic target for ischemic or traumatic brain injury. Exp Neurol. (2015) 272:17-25. doi: 10.1016/j.expneurol.2015.03.017

181. Chew LJ, King WC, Kennedy A, Gallo V. Interferon-gamma inhibits cell cycle exit in differentiating oligodendrocyte progenitor cells. Glia. (2005) 52:127-43. doi: 10.1002/glia.20232

182. Pizzi M, Sarnico I, Boroni F, Benarese M, Dreano M, Garotta G, et al Prevention of neuron and oligodendrocyte degeneration by interleukin- 6 (IL-6) and IL-6 receptor/IL-6 fusion protein in organotypic hippocampal slices. Mol Cell Neurosci. (2004) 25:301-11. doi: 10.1016/j.mcn.2003.10.022

183. Rodgers JM, Robinson AP, Rosler ES, Lariosa-Willingham K, Persons RE, Dugas JC, et al. IL-17A activates ERK1/2 and enhances differentiation of oligodendrocyte progenitor cells. Glia. (2015) 63:768-79. doi: 10.1002/glia.22783

184. Herx LM, Rivest S, Yong VW. Central nervous system-initiated inflammation and neurotrophism in trauma: IL-1 beta is required for the production of ciliary neurotrophic factor. J Immunol. (2000) 165:2232-9. doi: 10.4049/jimmunol.165.4.2232

185. Takahashi JL, Giuliani F, Power C, Imai Y, Yong VW. Interleukin-1beta promotes oligodendrocyte death through glutamate excitotoxicity. Ann Neurol. (2003) 53:588-95. doi: 10.1002/ana.10519

186. Saletti R, Reina S, Pittala MG, Belfiore R, Cunsolo V, Messina A, et al. High resolution mass spectrometry characterization of the oxidation pattern of methionine and cysteine residues in rat liver mitochondria voltage dependent anion selective channel 3 (VDAC3). Biochim Biophys Acta Biomembr. (2017) 1859:301-11. doi: 10.1016/j.bbamem.2016.12.003

187. Jin WN, Gonzales R, Feng Y, Wood K, Chai Z, Dong JF, et al Brain ischemia induces diversified neuroantigen-specific T-cell responses that exacerbate brain injury. Stroke. (2018) 49:1471-78. doi: 10.1161/STROKEAHA.118.020203

188. Wilkins A, Majed H, Layfield R, Compston A, Chandran S. Oligodendrocytes promote neuronal survival and axonal length by distinct intracellular mechanisms: a novel role for oligodendrocyte-derived glial cell line-derived neurotrophic factor. J Neurosci. (2003) 23:4967-74. doi: 10.1523/JNEUROSCI.23-12-04967.2003

189. Schmandke A, Schmandke A, Schwab ME. Nogo-A: multiple roles in CNS development, maintenance, and disease. Neuroscientist. (2014) 20:372-86 doi: $10.1177 / 1073858413516800$

190. Kaur C, Ling EA. Periventricular white matter damage in the hypoxic neonatal brain: role of microglial cells. Prog Neurobiol. (2009) 87:264-80. doi: 10.1016/j.pneurobio.2009.01.003

191. Hughes EG, Kang SH, Fukaya M, Bergles DE. Oligodendrocyte progenitors balance growth with self-repulsion to achieve homeostasis in the adult brain. Nat Neurosci. (2013) 16:668-76. doi: 10.1038/nn.3390

192. Hanisch UK, Kettenmann H. Microglia: active sensor and versatile effector cells in the normal and pathologic brain. Nat Neurosci. (2007) 10:1387-94 doi: $10.1038 / \mathrm{nn} 1997$

193. Miyamoto N, Pham LD, Seo JH, Kim KW, Lo EH, Arai K. Crosstalk between cerebral endothelium and oligodendrocyte. Cell Mol Life Sci. (2014) 71:1055-66. doi: 10.1007/s00018-013-1488-9

194. Seo JH, Miyamoto N, Hayakawa K, Pham LD, Maki T, Ayata C, et al. Oligodendrocyte precursors induce early blood-brain barrier opening after white matter injury. J Clin Invest. (2013) 123:782-6. doi: 10.1172/JCI65863

195. Hayakawa K, Pham LD, Katusic ZS, Arai K, Lo EH. Astrocytic high-mobility group box 1 promotes endothelial progenitor cell-mediated neurovascular 
remodeling during stroke recovery. Proc Natl Acad Sci USA. (2012) 109:7505-10. doi: 10.1073/pnas.1121146109

196. Egawa N, Lok J, Washida K, Arai K. Mechanisms of axonal damage and repair after central nervous system injury. Transl Stroke Res. (2017) 8:14-21. doi: 10.1007/s12975-016-0495-1

197. Zhang Q, Zhu W, Xu F, Dai X, Shi L, Cai W, et al. The interleukin4/PPARgamma signaling axis promotes oligodendrocyte differentiation and remyelination after brain injury. PLoS Biol. (2019) 17:e3000330. doi: 10.1371/journal.pbio.3000330

198. Choi JY, Kim BG. Toll-like receptor 2: a novel therapeutic target for ischemic white matter injury and oligodendrocyte death. Exp Neurobiol. (2017) 26:186-94. doi: 10.5607/en.2017.26.4.186

199. Tanaka K, Nogawa S, Ito D, Suzuki S, Dembo T, Kosakai A, et al. Activation of NG2-positive oligodendrocyte progenitor cells during postischemic reperfusion in the rat brain. Neuroreport. (2001) 12:2169-74. doi: 10.1097/00001756-200107200-00025

200. Song FE, Huang JL, Lin SH, Wang S, Ma GF, Tong XP. Roles of NG2-glia in ischemic stroke. CNS Neurosci Ther. (2017) 23:547-53. doi: $10.1111 / \mathrm{cns} .12690$

201. Chen P, Wang L, Deng Q, Ruan H, Cai W. Alteration in rectification of potassium channels in perinatal hypoxia ischemia brain damage. $J$ Neurophysiol. (2015) 113:592-600. doi: 10.1152/jn.00144.2014

202. Vande Velde C, Cizeau J, Dubik D, Alimonti J, Brown T, Israels S, et al. BNIP3 and genetic control of necrosis-like cell death through the mitochondrial permeability transition pore. Mol Cell Biol. (2000) 20:545468. doi: 10.1128/MCB.20.15.5454-5468.2000

203. Li C, Guan T, Chen X, Li W, Cai Q, Niu J, et al. BNIP3 mediates pre-myelinating oligodendrocyte cell death in hypoxia and ischemia. J Neurochem. (2013) 127:426-33. doi: 10.1111/jnc. 12314

204. He X, Li Y, Lu H, Zhang Z, Wang Y, Yang GY. Netrin-1 overexpression promotes white matter repairing and remodeling after focal cerebral ischemia in mice. J Cereb Blood Flow Metab. (2013) 33:1921-7. doi: $10.1038 /$ jcbfm. 2013.150

205. Li Y, Tang G, Liu Y, He X, Huang J, Lin X, et al. CXCL12 gene therapy ameliorates ischemia-Induced white matter injury in mouse brain. Stem Cells Transl Med. (2015) 4:1122-30. doi: 10.5966/sctm.20150074

206. Guo Z, Zhang L, Wu Z, Chen Y, Wang F, Chen G. In vivo direct reprogramming of reactive glial cells into functional neurons after brain injury and in an Alzheimer's disease model. Cell Stem Cell. (2014) 14:188202. doi: 10.1016/j.stem.2013.12.001

207. Michalski D, Keck AL, Grosche J, Martens H, Hartig W. Immunosignals of oligodendrocyte markers and myelin-associated proteins are critically affected after experimental stroke in wild-type and Alzheimer modeling mice of different ages. Front Cell Neurosci. (2018) 12:23. doi: 10.3389/fncel.2018.00023

208. Ortega SB, Noorbhai I, Poinsatte K, Kong X, Anderson A, Monson NL, et al. Stroke induces a rapid adaptive autoimmune response to novel neuronal antigens. Discov Med. (2015) 19:381-92.

209. Klehmet J, Hoffmann S, Walter G, Meisel C, Meisel A. Stroke induces specific alteration of $\mathrm{T}$ memory compartment controlling auto-reactive CNS antigen-specific T cell responses. J Neurol Sci. (2016) 368:77-83. doi: 10.1016/j.jns.2016.06.039

210. Frenkel D, Huang Z, Maron R, Koldzic DN, Hancock WW, Moskowitz MA, et al. Nasal vaccination with myelin oligodendrocyte glycoprotein reduces stroke size by inducing IL-10-producing CD4+ T cells. J Immunol. (2003) 171:6549-55. doi: 10.4049/jimmunol.171.12.6549

211. Romer C, Engel O, Winek K, Hochmeister S, Zhang T, Royl G, et al. Blocking stroke-induced immunodeficiency increases CNS antigen-specific autoreactivity but does not worsen functional outcome after experimental stroke. J Neurosci. (2015) 35:7777-94. doi: 10.1523/JNEUROSCI.1532-14.2015
212. Ren X, Akiyoshi K, Grafe MR, Vandenbark AA, Hurn PD, Herson PS, et al. Myelin specific cells infiltrate MCAO lesions and exacerbate stroke severity. Metab Brain Dis. (2012) 27:7-15. doi: 10.1007/s11011-011-9267-5

213. Choi EH, Xu Y, Medynets M, Monaco MCG, Major EO, Nath A, et al. Activated $\mathrm{T}$ cells induce proliferation of oligodendrocyte progenitor cells via release of vascular endothelial cell growth factor-A. Glia. (2018) 66:2503-13. doi: 10.1002/glia.23501

214. Zarriello S, Neal EG, Kaneko Y, Borlongan CV. T-Regulatory cells confer increased myelination and stem cell activity after stroke-induced white matter injury. J Clin Med. (2019) 8:537. doi: $10.3390 / \mathrm{jcm} 8$ 040537

215. Fernandez-Castaneda A, Chappell MS, Rosen DA, Seki SM, Beiter RM, Johanson DM, et al. The active contribution of OPCs to neuroinflammation is mediated by LRP1. Acta Neuropathol. (2019) 139:365-82. doi: 10.1007/s00401-019-02073-1

216. Harrington EP, Bergles DE, Calabresi PA. Immune cell modulation of oligodendrocyte lineage cells. Neurosci Lett. (2020) 715:134601. doi: 10.1016/j.neulet.2019.134601

217. Emery B. Regulation of oligodendrocyte differentiation and myelination. Science. (2010) 330:779-82. doi: 10.1126/science.1190927

218. Wang S, Sdrulla AD, diSibio G, Bush G, Nofziger D, Hicks C, et al. Notch receptor activation inhibits oligodendrocyte differentiation. Neuron. (1998) 21:63-75. doi: 10.1016/S0896-6273(00)80515-2

219. Brinkmann BG, Agarwal A, Sereda MW, Garratt AN, Muller T, Wende H, et al. Neuregulin-1/ErbB signaling serves distinct functions in myelination of the peripheral and central nervous system. Neuron. (2008) 59:581-95. doi: $10.1016 /$ j.neuron.2008.06.028

220. Zhang ZG, Zhang L, Jiang Q, Zhang R, Davies K, Powers C, et al. VEGF enhances angiogenesis and promotes blood-brain barrier leakage in the ischemic brain. J Clin Invest. (2000) 106:829-38. doi: 10.1172/JCI9369

221. Robin AM, Zhang ZG, Wang L, Zhang RL, Katakowski M, Zhang L, et al. Stromal cell-derived factor 1alpha mediates neural progenitor cell motility after focal cerebral ischemia. J Cereb Blood Flow Metab. (2006) 26:125-34. doi: $10.1038 /$ sj.jcbfm. 9600172

222. Arai K, Lo EH. An oligovascular niche: cerebral endothelial cells promote the survival and proliferation of oligodendrocyte precursor cells. J Neurosci. (2009) 29:4351-5. doi: 10.1523/JNEUROSCI.0035-09.2009

223. Prinz M, Priller J, Sisodia SS, Ransohoff RM. Heterogeneity of CNS myeloid cells and their roles in neurodegeneration. Nat Neurosci. (2011) 14:1227-35. doi: $10.1038 / \mathrm{nn} .2923$

224. Yu IC, Kuo PC, Yen JH, Paraiso HC, Curfman ET, Hong-Goka BC, et al. A combination of three repurposed drugs administered at reperfusion as a promising therapy for postischemic brain injury. Transl Stroke Res. (2017) 8:560-77. doi: 10.1007/s12975-017-0543-5

225. Tobin MK, Bonds JA, Minshall RD, Pelligrino DA, Testai FD, Lazarov O. Neurogenesis and inflammation after ischemic stroke: what is known and where we go from here. J Cereb Blood Flow Metab. (2014) 34:1573-84. doi: $10.1038 / \mathrm{jcbfm} .2014 .130$

226. Pettigrew LC, Kasner SE, Albers GW, Gorman M, Grotta JC, Sherman DG, et al. Safety and tolerability of arundic acid in acute ischemic stroke. J Neurol Sci. (2006) 251:50-6. doi: 10.1016/j.jns.2006.09.001

Conflict of Interest: The authors declare that the research was conducted in the absence of any commercial or financial relationships that could be construed as a potential conflict of interest.

Copyright $\odot 2020 \mathrm{Xu}, \mathrm{Lu}$, Shao, Zhang and Zhang. This is an open-access article distributed under the terms of the Creative Commons Attribution License (CC BY). The use, distribution or reproduction in other forums is permitted, provided the original author(s) and the copyright owner(s) are credited and that the original publication in this journal is cited, in accordance with accepted academic practice. No use, distribution or reproduction is permitted which does not comply with these terms. 